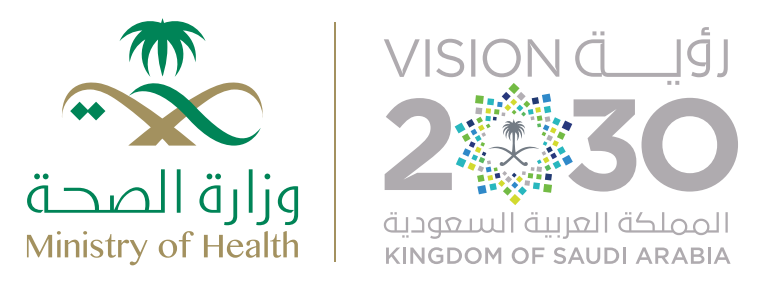

\title{
Health Sector
}

Transformation Strategy

V.3 



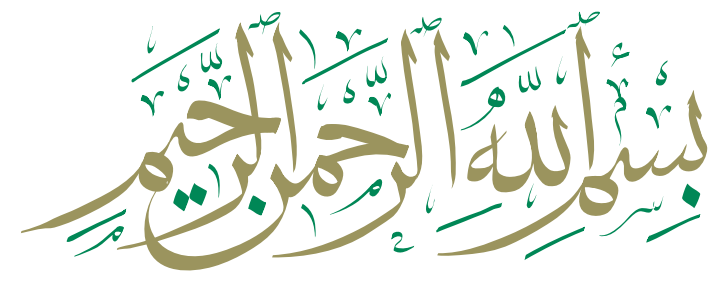




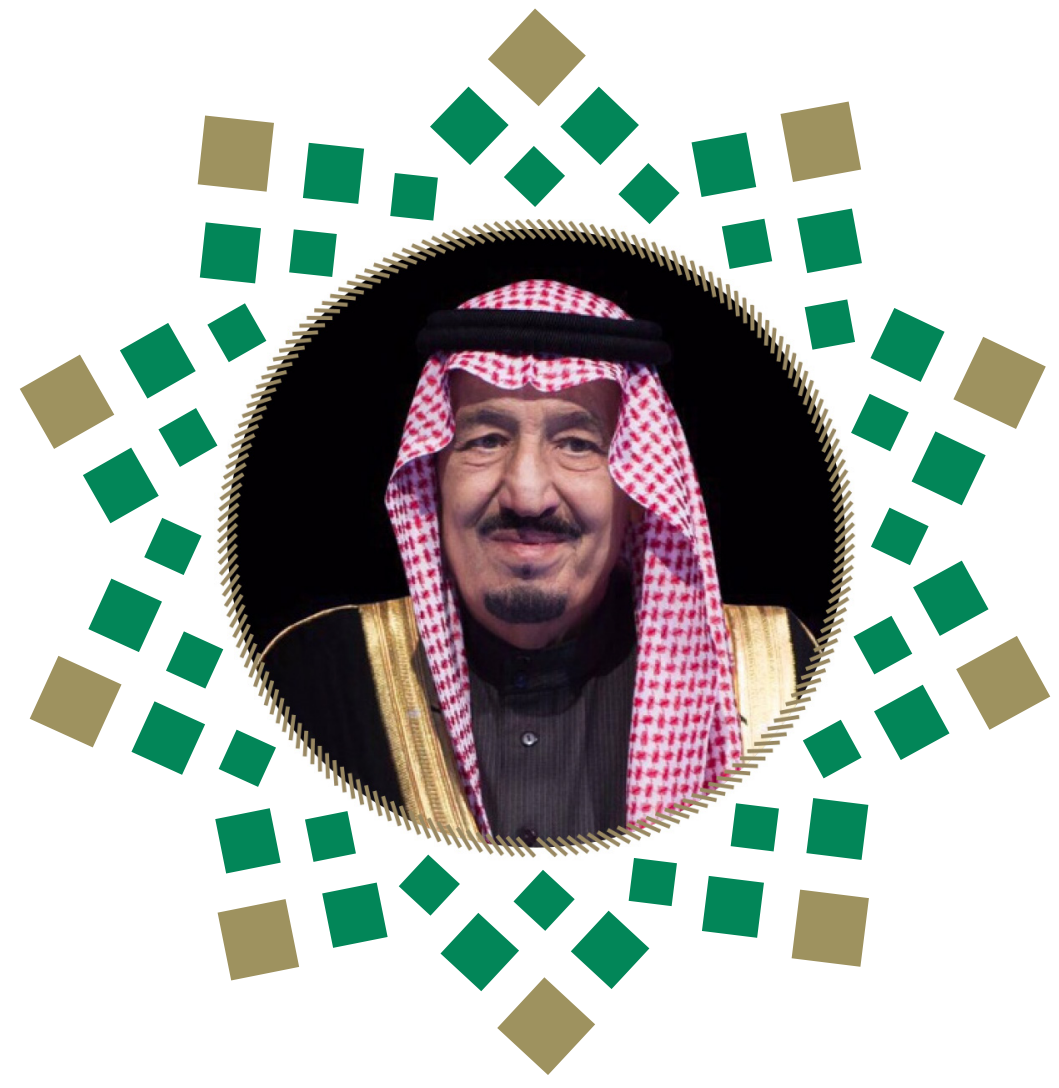

The Custodian of the Two Holy Mosques Salman bin Abdulaziz Al Saud 


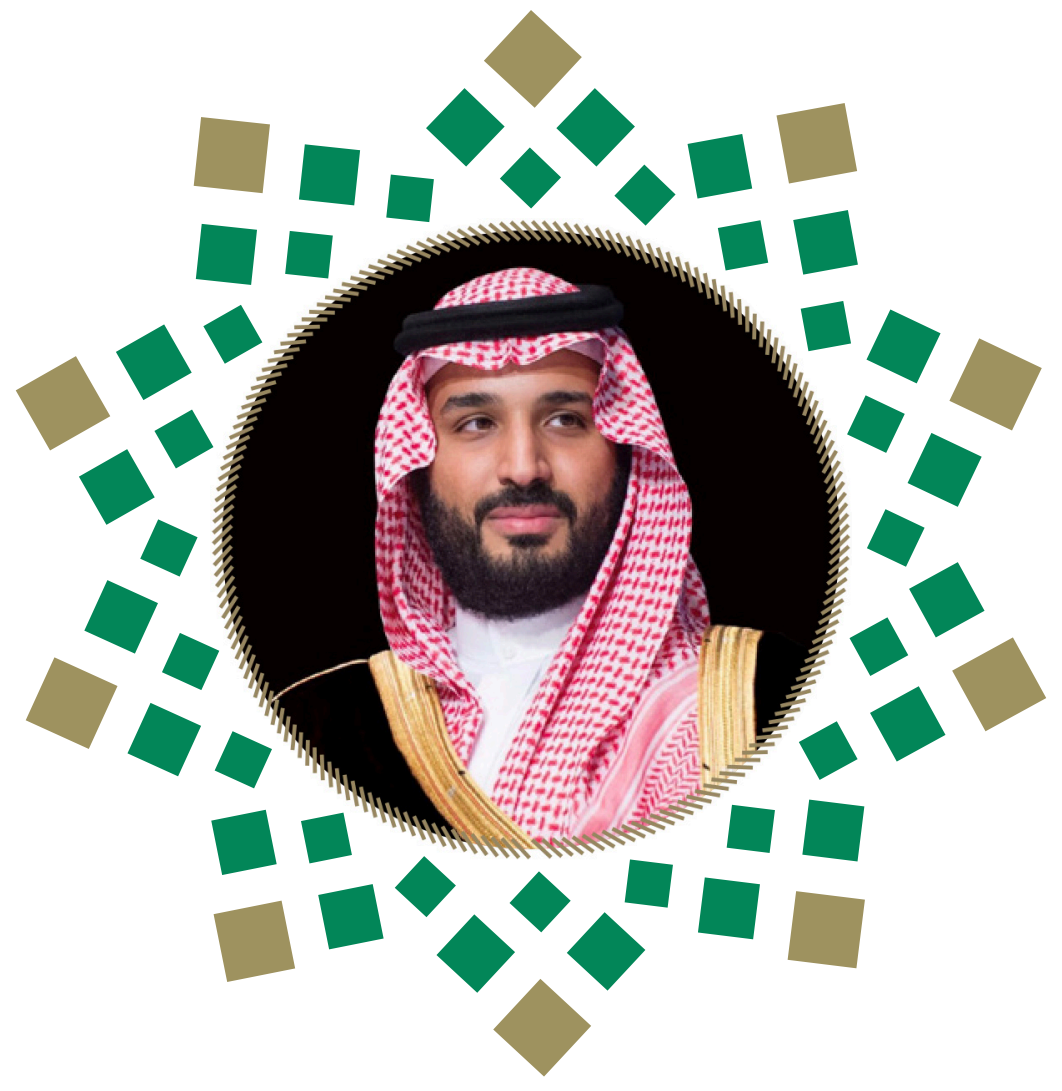

His Royal Highness Prince

\section{Mohammad bin Salman bin Abdulaziz Al Saud}

The Crown Prince, First Deputy Prime Minister and Minister of Defense 
Contents 


\section{Contents}

1. Introduction

2. The need for transformation

- Why do we want to change?

3. Defining the transformation goals and methods

- What do we want to change?

Using theory and applying it to our strategy.

4. Delivering the transformation

- How and when will things change?

5. Perceived risks and mitigations

29

- What do we want to avoid?

6. The economic case

32

- Do the benefits outweigh the costs?

7. Next steps

34

8. Annexes

35

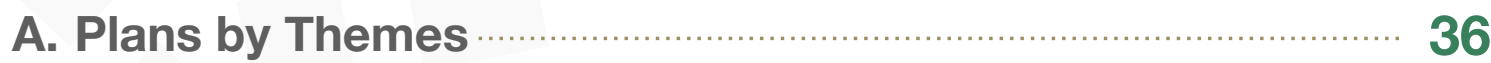

B. A description and summary analysis of the Harvard and Oxford Value frameworks

C. Bibliography of key documents (with hyperlinks)

63

D. Endnotes

64 
Introduction 


\section{Introduction}

Good health is a gift. Its promotion is amongst the greatest responsibilities of any State. We take that seriously and are now embarking on a fundamental transformation of our health system. Our country needs it. Our people deserve it.

Our population is growing. It's also growing older. Living longer is a blessing but it also brings challenges - as do our more diversified economy and increasingly urban lifestyles.

Every one of us has a role to play and our attitude towards our physical and mental wellbeing, as well as the system that supports it, must change if we are to achieve our ambition of living fulfilling lives in a vibrant society.

Future success relies on us being smart, sophisticated and less centralized. We must draw on what we've achieved in the past but not be held back by it. Healthcare staff need to be empowered to make the right decisions at the right time in the right place. They need the authority to take action, make choices and accept responsibility. They must also be given the chance to make honest, well-intentioned mistakes without undue fear of failure.

The scale and complexity of this transformation cannot be overstated. That is why it has been broken down into themes and will be executed in phases. We have sought to balance ambition and realism.

This paper gives an overview of the transformation, spelling out the underlying goals as clearly and coherently as possible. Delivering the strategy will be more complex and will only work if we can engage and co-ordinate large numbers of highly educated and skilled people effectively.

\section{Context}

The Ministry of Health $(\mathrm{MoH})$ has been tasked with delivering this strategy as part of "Vision 2030" for the Kingdom of Saudi Arabia [1]. This document addresses the Level 2 Strategic Objective of raising the standards of our health service, the Level 3 goals of easing access to it, ensuring better value and strengthening prevention against the main threats to our health. The strategy also aims to make a significant contribution to Level 2 Strategic Objective 2.2: Promote a healthy lifestyle.

Though led by the Ministry of Health; this plan has been developed in close collaboration with the National Transformation Program. 
The Need for Transformation

- Why do we want to change? 


\section{The Need for Transformation}

\section{Understanding the challenges [2]}

We have identified eight major challenges in our health system that need to be addressed over the coming decade.

1. The population of the Kingdom continues to grow and age. Our population is expected to rise from 33.5 million in mid 2018 to 39.5 million in mid 2030 . The number of elderly (aged 60 to 79 ) is expected to grow from 1.96 million in mid 2018 to 4.63 million in mid 2030.

In 2015 residents from overseas amounted to 30\% of the population of the Kingdom or 10 million people. These are mainly adults but also with some accompanying young people.

We have many overseas visitors too, particularly for the major religious festivals. Two years ago, 537,000 of those attending the Hajj were domestic pilgrims. 1,325,000 came here from abroad and in some years the total number of foreign pilgrims visiting Mecca has been estimated as high as three million people . [3]

The population of the KSA was $83.3 \%$ urban in 2016 , which is projected to rise to $85.9 \%$ in 2030.

2. Rates of avoidable injury and non-communicable disease remain high by regional and international standards. The Kingdom has made notable progress in improving the health of its population over recent decades, particularly in areas of child and maternal mortality and the reduction of communicable disease. For both males and females, life expectancy at birth improved from 64 years in 1970 to 75 years in 2015. There are targets set to ensure it increases to 80 years by 2030. But there is considerable scope to reduce avoidable mortality and avoidable morbidity in both the working and elderly populations. Particular areas of concern include heart disease, stroke, diabetes mellitus, respiratory disease, mental health, road traffic accidents and congenital diseases, all of which are amenable to reduction.

We need to strengthen the prevention of non-communicable disease and injury thereby reducing avoidable illness and death. The risk of major outbreaks of communicable disease also remains substantial, especially at Hajj or following natural or man-made disasters.

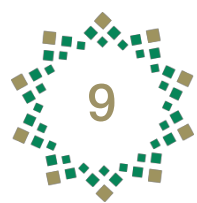




\section{The Need for Transformation}

When other government departments in the Kingdom develop major policy initiatives, the health and healthcare implications of their actions are not always at the front of their minds. Similarly, it has often proved difficult for the $\mathrm{MoH}$ to develop the inter-ministry dialogue necessary to resolve some of its own pressing problems.

3. Primary care remains inadequate and inconsistent. Secondary and tertiary hospitals, and associated resources, are poorly distributed across the Kingdom. [4] There is inadequate capacity in extended care services such as rehabilitation, long-term care and home care. These issues are compounded by low levels of productivity.

4. There are significant gaps in the quality of services provided to patients. Much of this is due to lack of consistent protocols and pathways for treatment, and incomplete measurement of patient processes and outcomes. The Saudi Central Board for Accreditation of Healthcare Institutions (CBAHI) Essential Safety Requirements Survey of 2015 has also emphasized key deficits in safety across all categories of hospitals.

5. There is unwarranted variation in provision, access and investment when assessed using the population served rather than the patients treated. This included over-use as well as under-use and leads to significant shortfalls in value as well as quality.

6. The system is currently resource and staff centric rather than patient or person centric in its orientation. It is also institution centric rather than population centric. A health system needs to be both accessible and responsive to patients' overall welfare.

7. There are significant gaps in workforce capacity and capability, specifically in relation to Saudi employees. The health system also currently lacks robust, consistent and integrated digital information systems to measure and manage resources, activity levels, quality and efficiency and to build a learning health system, in which all involved can contribute, share, and analyze data and in which continuous learning cycles encourage the creation of knowledge that can be used by a variety of health-information systems.

8. The health system also needs to support the containment of public expenditure, and the diversification of the Saudi economy. This is needed to address the risk of long term reductions in the price of crude oil and the impact that will have on public revenues.

The Kingdom therefore needs to:

- Encourage action within and beyond the health system to reduce injuries and the primary and secondary prevention of non-communicable diseases;

- Introduce comprehensive measures of population needs and health system performance to improve the allocation of resources and delivering the outcomes that people need; 


\section{The Need for Transformation}

- Create a culture of stewardship, in which all clinicians take responsibility for the use of resources, the prevention of waste and the long term sustainability of universal healthcare.

- Create incentives for staff and the system to be more effective, efficient and to encourage locally generated innovation;

- Facilitate levels of revenue and capital investment in healthcare facilities and systems that are proportionate to the Kingdom's economic status and are appropriately distributed to reflect population and patient needs;

- Bring transparency into the provision of care through systematic collection and internal reporting of clinical data, costs and outcomes at episode level, to understand and achieve better value;

- Ensure the quality and safety of clinical investigations and treatments, through system and process and the rigorous use of standards, protocols and clinical pathways and clinical practice guideline together with the continuous professional development of clinical and non-clinical staff;

- Ensure a broad-based, highly educated, skilled and highly productive healthcare workforce, staffed increasingly by Saudi citizens;

- Harness technology, the internet and mobile telephony, computational power and interoperability, big data and analysis to improve patient access, education and involvement in protecting and promoting their health, to drive quality and efficiency gains and to build a learning health system; and

- Develop the information systems, distributed governance systems, accounting systems, and the professional, employment and communication practices that will enable the $\mathrm{MoH}$ and the health system to be more responsive to current and future pressures. 


\section{Defining the Transformation Goals and Methods}

- What do we want to change?

Using theory and applying it to our strategy. 


\section{Defining the Transformation Goals and Methods}

\section{Our goals}

The proposed goals of the Transformation are to:

1. Improve health: Increase the length, wellbeing and quality of life of Saudi citizens, which includes the Vision 2030 goal of increasing the life expectancy of citizens to 80 years by 2030 ;

2. Improve healthcare: By improving the quality and consistency of services and the performance and accountability of healthcare organizations and staff to deliver care that is safe, effective, patient-centered, timely and equitable; and

3. Improve value: by containing costs, improving outcomes, controlling public healthcare expenditure and guiding new investment.

All three transformation goals conform with, and are enablers of, the Vision 2030 strategic objectives for health: access, value and public health.

These goals are also informed by international frameworks for the enhancement of health systems including:

- The World Health Organization health systems framework [5];

- The World Bank Group health systems framework [6];

- The Institute for Healthcare Improvement "Triple Aim" framework [7];

- National Academy of Medicine, "Vital Directions for Health and Healthcare [8] : and

- The NHS England "Five Year Forward View" strategic plan. [9]

\section{Introducing value based healthcare}

The transformation goals are consistent with the related, but distinct, frameworks for value based healthcare. These frameworks have been articulated by researchers at Harvard Business School. They are also closely associated with work by The World Economic Forum [10] which focuses on the implications for associated health industries and the somewhat distinct work at Oxford University, which has now been adopted in England, Scotland Wales and Italy. [11] 


\section{Defining the Transformation Goals and Methods}

This transformation strategy is deliberately formulated to utilize and combine aspects of all three value frameworks.

The financial, economic and institutional imperatives, together with the policy intentions of the KSA Government, that were expressed through Vision 2030, require a high level of overall control over health services expenditure and use of other resources. These factors also require a close interest in the health of the whole population. These considerations are distinctive features of the Oxford framework.

A description and summary analysis of the Harvard and Oxford Value frameworks can be found at Annex B.

\section{From theory to strategy}

The Vision Realization Office (VRO) has organized its work into seven themes:

- The New Models of Care;

- Provider reforms;

- Financing reforms;

- Governance development;

- Private and third sector participation;

- Workforce development; and

- eHealth development.

The first three themes can be understood as enablers of three levels of value:

- The "New Models of Care" theme as a focal point for enhancing personal value through the improvement of treatment and care modalities at an individual level.

- The provider theme as a focal point for enhancing utilization value at an intermediate level, whether that is at the clinical micro-system, hospital or local health system level. (The important principle in a country committed to universal healthcare is that the definition of the population captures everyone in a particular jurisdiction such as a region.) 


\section{Defining the Transformation Goals and Methods}

- The financing theme as a focal point for enhancing allocative value through ensuring those intermediate levels get "optimum" levels of resource, based on patients' needs and their ability to benefit.

It can be argued that financing plays a direct role in securing all three types of value. In addition, patients' needs are often qualified by other criteria including patients' merits, economic objectives to protect the health of the working population, or patients' ability and willingness to pay.

Past experience of health transformation strategies [12] suggests that organizational and financial changes are unlikely to lead to any major improvements in outcomes unless they are accompanied with supply side improvements, specifically, improvements in the efficiency, effectiveness, equity and responsiveness of the public health and health services provided. It is essential to recognize that the three value dimensions are interdependent and mutually reinforcing. Simply put, successful delivery of all the seven work themes will be essential to the overall success of our transformation strategy.

\section{Outlining the transformation strategy}

Through 2017 the $\mathrm{MoH}$ made progress in developing the principal elements of its strategy. The following section outlines key policies and links these to the challenges they seek to address. There is a particular emphasis on the first three themes. The subsequent parts of the paper examine in more detail how the key policies will be realized in practice.

\section{The New Models of Care [13]}

There are many challenges within the existing models of care for key patient pathways within the Kingdom. There are growing hazards within healthcare facilities due to inadequate medical quality and low safety standards. Waiting times are prolonged and they vary considerably across healthcare facilities, causing inevitable dissatisfaction. There are a number of high priority pathways with specific challenges including the maternity pathway, chronic conditions, planned care, urgent care, and last phase of life.

There are also challenges common to all pathways, including:

- Shortage of medications and available medicines are dispensed inconsistently;

- Lack of standardized clinical guidelines and variations in the quality and delivery of care;

- Poor pathway management, with inappropriate referrals, and inappropriate presentation by ill-informed patients disrupting patient flow; 


\section{Defining the Transformation Goals and Methods}

- Lack of out-of-hospital services for diagnostic, preventative, proactive or follow-up care;

- Poorly coordinated care, particularly between $\mathrm{MoH}$ providers and non-governmental organizations; and

- Poor communication between providers, and between clinicians and patients.

To address these challenges, the $\mathrm{MoH}$ has developed a program to design, pilot, and implement a patient centric New Models of Care Program.

The program has been designed to answer six key questions:

1. How will the system help to keep me well?

2. How will the system support me when I have an urgent problem?

3. How will the system support me to have a great outcome for my planned procedure?

4. How will the system support me to safely deliver a healthy baby?

5. How will the system support me with my chronic conditions?

6. How will the system support me with compassionate care during the last phase of my life?

The New Models of Care is designed to support people with their health and wellness needs: physical wellbeing, mental wellbeing and social wellbeing. This aligns with the principles set out in the Constitution of the World Health Organization: "health is a state of complete physical, mental and social wellbeing and not merely the absence of disease or infirmity".

Virtual care will be a powerful source of health advice. Virtual care in most instances will serve as people's first point of contact with medical care providers, improving people's access to medical advice and guiding them to navigate the healthcare system and seek appropriate care.

The New Models of Care program has been designed based on the following principles:

- Empowering people and their families to take control of their health;

- Providing knowledge to people as part of their treatment, and enabling them to be well-informed and in control of their health;

- Fully integrating the health system from the people's perspective; 


\section{Defining the Transformation Goals and Methods}

- Keeping people healthy and focusing on the whole population through a preventive approach, rather than a solely curative approach to health provision; and

- Providing treatment in a patient-friendly and outcome-focused way, without overtreating or under-treating patients.

Accordingly, it has been developed with patient needs and asks at the center of the whole system.

The New Models of Care Program will deliver 42 coordinated interventions, across six 'systems' of care by the end of 2020.

The prioritized systems of care are: Keep Well, Safe Birth, Planned Care, Urgent Care, Chronic Conditions and Last Phase.

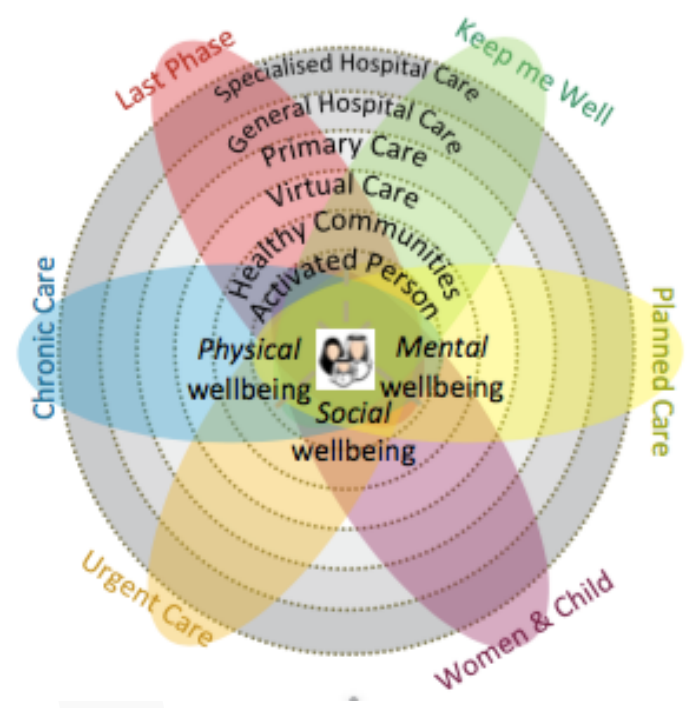

The 42 initiatives will include defined patient pathways and key performance indicators (KPIs) including measurement of: safety and quality process metrics, clinical and patient reported outcomes, and financial performance. These New Models of Care KPIs will be incorporated into the KPIs for the Essential Benefits Package (EPB) (see Financing below) to ensure that they are monitored and maintained when achieved. (A full list of the 42 interventions, progress to date and next steps is contained in Annex A). 


\section{Defining the Transformation Goals and Methods}

\section{Provider reform [14]}

Key policies include:

- Developing all existing $\mathrm{MoH}$ providers, through an initial "cluster" phase, into approximately 20 geographically defined, vertically integrated "Accountable Care Organizations (ACOs);"

- Making increased use of private healthcare provision; and

- Developing third sector provision to cover gaps arising from either government or market failure.

The ACOs will be established as "corporatized" public bodies, with substantial and clearly defined "decision rights". Responsibility and accountability for the successful management and clinical governance of the ACOs will be vested in Boards which will be established in each ACO. The Chairman of each ACO Board will be appointed by the Minister of Health.

The NHS in England has had a policy of corporatizing public healthcare providers since at least 2004. This builds on a key textbook on reforming public hospitals published by The World Bank in 2003. [15] This Strategy is drawing widely on the English experience including its guidance on board led governance. [16]

ACO Boards will become the focal point for the successful realization of utilization value in the system. Each ACO will also have to take responsibility for the allocation of resources for their population.

The precise decision rights of the Saudi ACOs are still being determined. The more extensive the rights, the more scope that ACOs Board will have to improve use and personal value within their geographies and institutions.

Confirmed decision rights of ACO Boards include:

- Salaries and salary structures (clinical and non-clinical); and

- Employment rights over staff, including monitoring and evaluation of clinical and managerial performance. 


\section{Defining the Transformation Goals and Methods}

Other issues that should be considered include:

- Rights to acquire, dispose of, and invest in physical assets;

- Rights to generate income (adjacent to core activities);

- Rights to set up educational courses and establishments (particularly nursing schools); and

- Financial rights and responsibilities (e.g. handling of surpluses, ability to take on debt).

Well performing ACO Boards, with appropriate decision rights, will be central to addressing the identified challenges within their geographies:

- Insufficient and poorly distributed capacity and capabilities in the provision of public health, primary care, secondary, tertiary care and extended care services;

- Key deficits in the appropriateness, quality, safety, effectiveness and efficiency of services provided, including workforce productivity;

- Gaps in workforce capacity and capability, and specifically in relation to Saudi employees; and

- Unwarranted variation either in comparison with other population based ACOs or within the ACO.

ACO Boards will also play a vital role in the robust local adoption of digital information systems. These will measure and manage resources, activity levels, quality and efficiency and build a learning health system.

Finally, ACO Boards will have an important responsibility for ensuring that ACO staff and institutions become patient or person centric in their orientation. They will do that both by personal example and through their behavior and decisions as a Board. 


\section{Defining the Transformation Goals and Methods}

\section{Financing reform $[17,18]$}

Key policies, to be achieved in incremental steps, include:

Confirmed commitment to universal healthcare coverage which will ensure that all citizens, residents and visitors to the Kingdom can obtain timely access to healthcare services, via insurance, without the risk of impoverishment;

- $\quad$ Establishing the program for health assurance and purchasing to be a national payor to ensure free care to beneficiaries through the newly $\mathrm{MOH}$ corporatized providers and other governmental providers.

- Definition of an Essential Benefits Package (EBP) which clearly defines a core package of treatment and care (with defined quality standards) that all insured patients will ultimately become entitled to;

Creating a system of supplementary health insurance $(\mathrm{SHI})$ which will allow most citizens and residents to add additional benefits to their EBP. This SHI could be used to enhance the scope, timeliness or comfort of their treatment and care;

- Creating a wider role for private health insurers as the transformation matures, through the creation of a market of licensed and regulated insurers who will offer SHI products.

Payment mechanisms that will support the implementation of the New Models of Care and ensure value at all levels.

Analyzing spend by major program budget at a national and regional level to optimize the allocation process;

The definition of an EBP will improve the allocation of resources and ultimately ensure that the whole population receive a guaranteed level of timely and accessible treatment and care. This will include services that that can achieve primary and secondary prevention of disease. 


\section{Defining the Transformation Goals and Methods}

\section{Governance development}

The policy goals of the governance theme are:

1. To define, design and support the establishment of the regulatory and improvement functions and institutions necessary to secure and sustain value based healthcare.

2. To embed strong, delegated and devolved leadership and governance throughout the health system. The Kingdom is too large, and the challenges are too many, complex, dynamic and inter-connected to be addressed successfully solely by a centralized bureaucracy, however competent.

A detailed description of the development approach of this work theme can be found in Annex A.

\section{Capacity and capability building}

The other three themes of the strategy are all related to aspects of capacity and capability building:

The policy goals of private sector participation on the supply/service provision side are:

- To reduce pressures on public funds;

- To provide performance benchmarks for corporatized providers; and

- To potentially facilitate partnership opportunities for corporatized providers to divest and re-invest to enhance service quality or efficiency.

The policy goal of associated third sector participation is:

- To fill any residual gaps in treatment, care or support services, highly valued by patients and their families, that would otherwise persist in the presence of government and market failures. (e.g. hospice services).

The policy goal of the eHealth program is:

- To support the information requirements of the other work themes and, in particular, to enable a value based healthcare approach and build a learning health system. 


\section{Defining the Transformation Goals and Methods}

A value based healthcare information architecture includes the following minimum components [19] :

- Standardized outcome metrics and accurate measurement of resource costs by population segment (segmenting the population by need as well as by geography);

- A universal data taxonomy across diseases and population groups (e.g. a consistent methodology and scale for measuring pain or patient quality of life);

- Inter-operability that allows databases to efficiently communicate with each other;

- Integration of outcomes data into the systems clinicians use in their daily work (e.g. electronic medical records [EMRs]) with a user-friendly interface that minimizes the effort required for entering data;

- Mechanisms to link individual patient data across multiple databases (e.g. a unique personal identifier); and

- Robust governance processes, with comprehensive

rules for data access, agreements about data sharing and guidelines for managing privacy.

The policy goal of the workforce development program is:

- to support the transformation of the workforce necessary to enable a value based healthcare approach. This will require major increases in workforce capability and some increase, re-distribution and diversification of workforce capacity. 


\section{Delivering the Transformation - How and when will things change?}




\section{Delivering the Transformation}

\section{Timeline and scope of the transformation}

The reforms will be implemented in three broad phases, of increasing scope and complexity:

\section{Phase 1 - Building capabilities}

Phase 1 is underway. It commenced at the beginning of 2018 and will finish at the end of 2020. This phase is primarily concerned with clinical systems improvement, capacity and capability building and preliminary institution building.

From a financing perspective, Phase 1 envisages the establishment of a government mandated, Purchasing Program (PP), managed by new department, initially based within the Ministry of Health. The PP will initially cover persons already covered by $\mathrm{MoH}$ services, who will be offered entitlements defined in the Essential Benefits Package (EBP).

From a delivery perspective, Phase 1 envisages the establishment of a corporatized public Holding Company with a number of associated regional Corporates. The Holding Company will be responsible for the creation of approximately 20 , vertically integrated, geographically defined, clusters of providers.

The present plan is that the clusters will be established in "waves." Wave 1, comprising five clusters will be initiated during 2018. The first cluster will be in the Eastern Region, the second and third in Riyadh, the fourth in Makkah. The location of the fifth cluster will be Qasim. Subsequent waves of clusters will be initiated by the Corporates, at a pace that they will determine.

The Phase 1 reforms, from both financing and delivery perspectives, will be heavily informed by ongoing work coordinated by, the $\mathrm{MoH}$-Vision Realization Office (VRO) on New Models of Care. This includes the 42 initiatives proposed by the $\mathrm{MoH}$ during the latest round of revisions (July to October 2017) to the National Transformation Plan.

\section{Phase 2 - Developing autonomy and value}

Phase 2 will start at the beginning of 2021 and finish at the end of 2025. This phase is primarily concerned with the secure and robust corporatization of key public entities. These include the ACOs (developed from the clusters), PHAP in Phase 2, and a range of regulatory and improvement agencies.

Phase 2 will also include the re-purposing of the $\mathrm{MoH}$; the implementation of Health in All policies; and the implementation of system wide enabling reforms regarding workforce, digital and systems governance. 


\section{Delivering the Transformation}

From a financing perspective, Phase 2 envisages the possible extension of the PHAP to persons presently funded by all other government departments including Other Government Services (OGS).

During Phase 2 most persons covered by the PP will be given the opportunity to purchase supplementary health insurance $(\mathrm{SHI})$.

From a delivery perspective, clusters will be developed into approximately 20 corporatized ACOs across the Kingdom. The ACOs will primarily be resourced from existing $\mathrm{MoH}$ services and facilities. However, the ACOs will also be able to sub-contract services for patients covered by the PHAP (and SHI) from the private sector. It is also envisaged that healthcare facilities and staff presently directly managed by other government departments may be fully or partly integrated into emerging ACOs during Phase 2.

\section{Phase 3 - Strengthening value and choice}

Phase 3 will start at the beginning of 2026 and finish at the end of 2030 .

From a financing perspective, Phase 3 envisages the extension of the $\mathrm{NHI}$ to all citizens, residents and visitors to the Kingdom. It envisages the simultaneous push of licensed private health insurance providers to embrace and implemented the principles of value based healthcare. 


\section{Delivering the Transformation}

\section{Change management}

The change proposed in this strategy is transformational. It involves altering the overall orientation of the $\mathrm{MoH}$ and wider health system. It entails changing the purposes of the system, types of work, roles and ways of working, learning, culture and organizational processes. It is also: multi-dimensional, multi-level and multi-phase. The transformation as envisaged is, appropriately, both planned and emergent.

The transformation also takes place in the context of an "open system". This is a system that cannot be fully controlled and must also interact with, and react to, a range of uncertain and sometimes unpredictable and unknown factors beyond its control. As such no single change management theory or framework will be adequate for all aspects of the transformation.

Nonetheless, the core governance of the transformation requires a consistent approach to change management. This approach must be appropriate to deliver a transformation that is complex, emergent, and open. [20]

It is therefore proposed that two change management approaches will be incorporated at every level.

The first approach is Edward Deming's model for quality improvement, with its embedded continuous improvement cycle. In this approach, process mapping and analysis of progress are supplemented by qualitative and quantitative analysis.

The second, complementary approach, is that of action research and learning, with its emphases on learning through action, process development "facilitation" (co-production) and collaborative learning. This approach is especially appropriate in the highly professionalized and specialized arena of healthcare, but should also extend to involving citizens and patients.

There are, nonetheless, broadly two dimensions to the change management outlined above: internal change management and external change management. Systems leaders have more, but not complete, control over the former, less over the latter. These levels of control will have an effect over the style of change management process adopted by different work streams. This point is illustrated below by outlining the proposed change management approaches that have been adopted by the corporatization and eHealth workstreams.

It will be important that the VRO and $\mathrm{MoH}$ leadership keeps approaches to change management adopted by themselves, and their associated Boards, under regular review. This will ensure that approaches are adjusted, and remain appropriate, effective and aligned, as the transformation progresses. 


\section{Delivering the Transformation}

Corporatization Delivery Office - Approach to change management

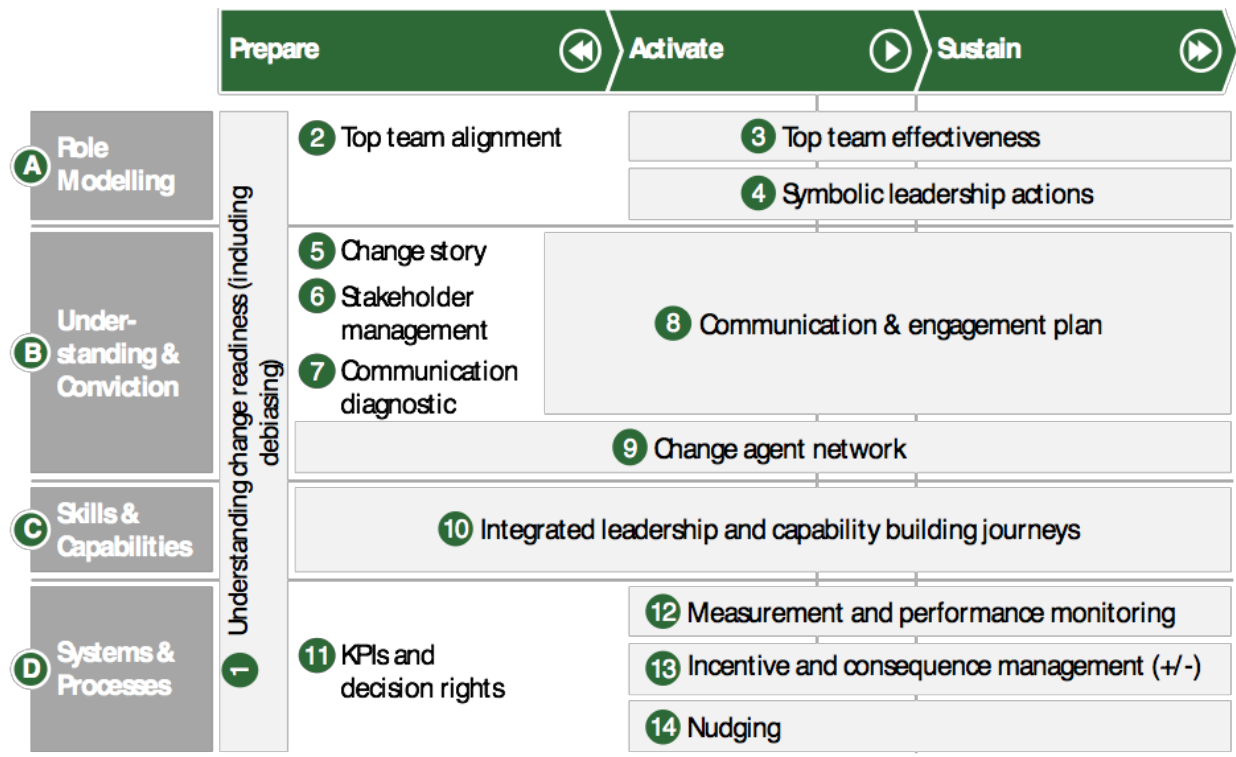

eHealth - Approach to change management

\begin{tabular}{|c|c|}
\hline \multicolumn{2}{|r|}{ Prosci's ADKAR Change Management Framework } \\
\hline Awareness & $\begin{array}{l}\text { - Why isthe change necessary? } \\
\text { - What are the businessreasonsfor the change? } \\
\text { - Are people aware of these reasons? }\end{array}$ \\
\hline Desire & $\begin{array}{l}\text { - What are the factors/ consequenœs (good or bad) that will } \\
\text { motivate the change? } \\
\text { - How do the motivat ingfact orsweigh against the inertia? }\end{array}$ \\
\hline Knowledge & - What skills/knowledge are requiredto support thechange? \\
\hline Ability & $\begin{array}{l}\text { - Doeseveryone possessthe skill//knowledge required to support } \\
\text { the change? } \\
\text { - If not, how will they be acquired/disseminat ed? }\end{array}$ \\
\hline Peinforcement & $\begin{array}{l}\text { - How will the change be sust ained (i.e. inœntives, } \\
\text { consequences, maintenanœ, governance, etc)? }\end{array}$ \\
\hline
\end{tabular}

A fuller description of the plans for each theme can be found at Annex A. 


\section{Perceived Risks and Mitigations - What do we want to avoid?}




\section{Perceived Risks and Mitigations}

\section{Identifying Risks}

The key tests for any strategy are that:

1. Identified challenges are adequately addressed;

2. Defined goals can be achieved;

3. Enabling policies and related initiatives are SMART (specific, measurable, achievable, realistic and timely); and

4. That the strategy is coherent; and the individual elements well aligned with each other.

The risks associated with this transformation strategy can be divided into three broad categories:

- Design risks - Where the design of the strategy is flawed in certain respects:

- Implementation risks - Where the design is good but implementation is weak;

- Operational risks - Where design is good, implementation is sound but operational performance of the new system is impeded by anticipated or unanticipated operational risks.

Design risks are being mitigated within each work theme using experienced leading management consultants. "Gateway" review processes are already in place.

Increased emphasis is also being placed on the overall coherence and alignment of the strategy. The leadership and partners of the management consultants are working together closely on alignment planning. There are frequent and regular internal "Design Authority" meetings, which also periodically review the continuing overall coherence of the transformation as detailed plans evolve.

Another, very important design risk mitigation strategy is the systematic use of national and international advisory boards composed of leading experts to advice and inform the progress of the strategy. In addition, international organizations are engaged in the review of the overall strategy and the strategies of individual workstreams. Key organizations involved include the World Bank Group, Harvard University (School of Public Health) and the London School of Economics.

Implementation risks are being identified and addressed. Risk registers are being assembled at work theme and VRO levels. 


\section{Perceived Risks and Mitigations}

\section{Key perceived risks (as of Q2 2018)}

\section{Immediate risks}

- Present and future gaps in workforce capacity and capability. Mitigation Request for proposal tendered to strengthen workforce planning capabilities.

- Evaluate if all value based healthcare eHealth prerequisites have been included in eHealth plan; and fill any gaps. Mitigation - Evaluation commenced

- Low and late investment rates (challenges in securing timely and proportionate investment in the strategy, for example some aspects of New Models of Care remain thin, particularly mental health services). Mitigation Dialogue with the Ministry of Finance and the Ministry of Economy and Planning though NTP channels.

\section{Future risks}

- Uncertainty regarding timing and nature of integration of other government services into the transformation strategy. Mitigation - Dialogue being progressed through the Saudi Health Council (SHC).

- If the scope decision rights given to "corporatized" entities (e.g. ACOs and regulators) are too narrow and low the corporatization will be costly but ineffective. Mitigation - Risk recognized and appropriate decision rights still being evaluated. 
The Economic Case

- Do the benefits outweigh the costs? 


\section{The Economic Case}

\section{The Economic Case [21]}

The economic case for the transformation of the health system was first modeled in March 2017, and revised in May 2017. Both versions were based on needs and investments agreed in National Transformation Programme 1.

A third, more detailed modeling was conducted in May 2018, based on investments proposed in National Transformation Programme 2 (July to October 2017).

The May 2017 modeling generated a benefit to cost ratio of 4.6 for the $\mathrm{MoH}$ and 10.9 for the $\mathrm{MoH}$ and the wider KSA economy, on the calculation that investment costs in the transformation would be SAR 65 Bn (SAR 55 Bn NPV discounted)).

In the same May 2017 modeling, the benefit of increasing the scope of reform to system wide transformation (from Phase 2), were estimated to increase the benefit to cost ratio from 4.6 to 5.2 for the $\mathrm{MoH}$ (and from 10.9 to 11.3 for the $\mathrm{MoH}$ and the wider KSA economy). The investment costs of system wide transformation however were estimated to rise to SAR 129 Bn (SAR 111 Bn NPV discounted).

The initial, provisional, output of the May 2018 modeling, suggests a more modest, but still positive benefit to cost ratio of 1.8 for the $\mathrm{MoH}$.

It is important to note that the total investment level in the May 2018 modeling is 6 times higher than in Business Case Version 1 at SAR 356 Bn cumulative to 2030 (compared with SAR $65 \mathrm{Bn})$.

This in turn reflects the wider range of service gaps that are being addressed by investments in the May 2018 modeling, and scale of quality improvement envisaged to be delivered.

It is also important to understand that the May 2018 modeling would still envisage reducing the projected annual operating budget of the $\mathrm{MoH}$ in 2030 from SAR $178 \mathrm{Bn}$ (Do Nothing scenario) to SAR $126 \mathrm{Bn}$. 
Next Steps 


\section{Next Steps}

\section{Next Steps}

Key next steps during 2018 include:

\section{Vision Realization Office leadership}

- Proactive communication of the transformation strategy to professional and public audiences.

\section{Reforms to the New Models of Care}

- Commencement of the majority of the 42 New Models of Care initiatives by end 2018.

- Procurement pathway for Patient Reported Outcome Measures (PROMs) defined and agreed by end 2018.

\section{Provider reform}

- The establishment of the provider Holding Company and Corporates by end 2018 .

- Commencement of cluster rollout in the Eastern and Central Regions by end 2018.

Financing reform

- The establishment of the "purchasing entity", initially within MoH by mid 2018.

- Enrollment of "members" in order to commence Purchasing Program on 1 January 2019.

\section{Governance development}

- Governance work-streams (See Annex A) completed.

- Pilot Leadership Program completed and substantive Executive Leadership Program commenced by end 2018.

\section{Private sector participation}

- New "White Paper" on emergent private sector participation priorities completed and agreed by mid 2018.

\section{Workforce development}

- Initial quantitative evaluation of workforce capacity and capability requirements to 2030 completed and requirements agreed by end 2018.

eHealth development

- Specified 2018 projects (defined on pages 54 to 55) commenced by end 2018.

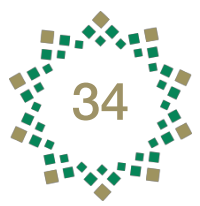




\section{Annexes}

A. Plans By Themes

B. A description and summary analysis of the Harvard and Oxford Value frameworks

C. Bibliography of key documents (with hyperlinks)

D. Endnotes 


\section{Annexes}

\section{Annex A. Plans by Themes}

\section{New Models of Care}

The New Models of Care Program will deliver 42 coordinated interventions, across the six systems of care. These 42 interventions are listed below:

\section{Keep Well}

The system will support people to stay well, and get well again, providing them with knowledge, empowering them and supporting them with healthy communities. It will achieve this through:

1. Health coach programs;

2. Community-based wellness programs;

3. Workplace wellness programs;

4. School wellness programs;

5. Healthy food promotion;

6. Health edutainment programs; and

7. Promoting the Saudi Centre for Disease Control.

\section{Planned Care}

The system will support patients to receive a great and consistent outcome for planned procedures, by providing necessary, efficient, and high quality care. It will achieve this through:
8. One-stop clinics;
9. Pathway optimization;
10. Length of stay reduction initiatives; and
11. Step-down and post-discharge services.

\section{Safe Birth}

The system will support women to have a safe delivery and healthy infants. It will provide continuous support from pre-marriage and pre-conception to post delivery and during early years development. It will achieve this through:

12. Premarital screening;

13. Preconception care services;

14. Maternity care services;

15. National birth registry;

16. Postnatal care services;

17. Well baby clinics; and

18. Neonatal care services. 


\section{Annexes}

\section{Urgent Care}

The system will support people when they have an urgent problem by providing the necessary treatment in the right place, at the right time, and by supporting patients return home and to community services. It will achieve this through:

19. A resource control center;

20. Urgent care clinics; and

21. Population-based critical care centers.

\section{Chronic Conditions}

The system will support people to manage their chronic conditions by providing integrated care, facilitate the patient flow between care setting, and by promoting care at the appropriate setting. It will achieve this through:

22. Chronic disease screening;

23. Case co-ordination; and

24. Continuing care services.

\section{Last Phase}

The system will support patients and their families during the last phase of their lives. It will provide them with compassionate care and empower them to spend their last days at a place of their choice. It will achieve this through:

25. Patient and family support;

26. Hospice care services; and

27. Multidisciplinary team development.

\section{Cross Cutting interventions}

28. Health in all policies;

29. Virtual self-care tools;

30. Virtual education and navigation tools;

31. Health hotline services;

32. Healthy living campaigns;

33. School education programs;

34. Enhanced primary care services;

35. Enhanced home care services;

36. Resource optimization;

37. Integrated personal health records;

38. National referral networks;

39. National guidelines;

40. Outcomes monitoring;

41. Systematic data collection; and

42. Health research programs 


\section{Annexes}

While development of the New Models of Care program is being coordinated nationally, it is intended that the interventions will be adaptive to different contexts (e.g. city, town, rural).

How these interventions will be adjusted to respond to greater demand during the religious festivals will need to be considered.

The national team will also need to consider how mental health needs should be taken into account, as these services are comparatively less developed.

\section{Progress to date}

Design of Models of Care (Phase 1 took place between October 2016 and April 2017. The Vision Realization Office (VRO) New Model of Care team led a national effort including more than 450 health professionals and patients, with an additional 2,000 involved in virtual discussions. These stakeholders worked together to shape the New Models of Care.

Regional Pathway Development (Phase 2) ran from April to August 2017. It focused on working with five pathfinders to develop the national system of care designs into the following implementable regional pathways:

- King Saud Medical City (KSMC), Riyadh: Women and Child (and Planned Procedure);

- King Fahad Medical City (KFMC), Riyadh: Last Phase (and Planned Procedure);

- King Khalid Eye Specialist Hospital (KKESH), Riyadh: Planned Procedure (in conjunction with KSMC and KFMC in Riyadh);

- King Abdullah Medical City (KAMC), Makkah: Urgent Problem; and

- King Fahad Specialist Hospital - Dammam (KFSH-D), Dammam: Chronic Conditions (starting with hypertension and sickle cell disease).

A national implementation team is working with task forces of experts to implement the Cross-Cutting and Keep Well systems.

\section{Next steps}

Implementation (Phase 3) is expected to occur in waves, in regional hubs in tandem with the development of the Corporates. 


\section{Annexes}

\section{Provider reforms}

\section{Initiating provider reform}

Provider reform will be initiated by the creation of a parent Holding Company responsible for managing existing $\mathrm{MoH}$ providers.

The next step will require the Holding Company to execute plans to establish five regional offices, known as Corporates. These will in turn manage the establishment of a total of $\sim 20$ geographic clusters as quickly and effectively as possible. The purpose of the Corporates will be to support the development of the clusters into autonomous, public corporations to by the end of 2030 .

The VRO corporatization work-stream plans to establish the Holding Company by the end of Quarter 22018 and the Five Associated Corporates at the same time. The clusters will be developed in waves.

Wave 1, comprising five clusters, will be initiated during 2018. The first cluster will be in the Eastern Region, the second and third in Riyadh, the fourth in Makkah. The location of the fifth is Qasim. Subsequent waves of clusters will be initiated by the five Corporates, at pace that they will determine.

The key initial requirements leading to the development of the clusters include:

- Integration of existing providers;

- The development of cluster level leadership, strategic management and governance skills;

- The development of public engagement capabilities; and

- The development of information, financial and management systems.

An initial risk and readiness assessment for wave 1 clusters has been undertaken that considered disruption to patient services, staff redeployment and finances. The VRO provider reform work theme is now setting up corporate delivery offices which will work on building capacity at a local level. This will ensure each cluster will have the necessary competencies and level of autonomy expected of a well-functioning health system.

\section{Corporatization and the establishment of Accountable Care Organizations (ACOs)}

It is planned that clusters will establish Advisory Boards at the earliest opportunity. These Advisory Boards will be confirmed (once legal structures allow) as Cluster Boards, who will guide and support clusters towards the competencies and capabilities required to become corporatized Accountable Care Organizations. Clusters will take on the responsibilities of ACO status when they have the capabilities to do so. 


\section{Annexes}

\section{The role of medical cities}

There are currently several medical cities and specialized hospitals in the KSA. Many of these are being used as pathfinders for New Model of Care initiatives (see below).

It is proposed that King Fahad Medical City and King Saud Medical City are incorporated within Clusters 1 and 2 of the Central (Region) Corporate. King Abdallah Medical City is incorporated within Cluster 1 of the Western (Region) Corporate. In the Eastern Region, the King Fahad Specialist Hospital in Dammam will be incorporated within Cluster 1 of the Eastern (Region) Corporate.

Plans regarding the other medical cities and specialized hospitals (e.g. King Khalid Eye Specialist Hospital) are being developed by the corporate delivery offices in collaboration with the respective medical cities.

\section{Ambulance services}

The New Model of Care trauma pilot program is providing an opportunity to consider priorities for the wider development of ambulance services. Pre-hospital treatment and care is a vital component of trauma services. The VRO intends to work closely with the Red Crescent Authority and other stakeholders on this and related matters in 2018 and 2019. 


\section{Annexes}

\section{Financing reform}

\section{Purchasing Program coverage}

During Phase 1 the PHAP will cover all persons presently eligible for Ministry of Health $(\mathrm{MoH})$ services. This includes:

Saudi citizens covered by $\mathrm{MOH}$ services unless covered by program provided to them by entities other than $\mathrm{MOH}$;

- Saudi citizens covered by private health insurance under the Council for Cooperative Health Insurance (CCHI) Scheme (but only for services in the Essential Benefits Package (EBP) that are not covered through their private health insurance package);

- Expatriates and their dependents working directly for the KSA Government; and

- Any group that are included in the coverage by a legal resolution.

- The EBP will specify:

- Type of services - the scope of clinical services provided;

- Utilization standards - processes to control utilization levels (e.g. referral pathways);

- Amenity levels - the level of amenity of services provided (e.g. when shared or single hospital rooms will be provided); and

- Provider network - the service providers that will deliver clinical services.

The EBP will include all services presently included in the $\mathrm{CCHI}$ benefit package, together with additional services based on current $\mathrm{MoH}$ practices and international benchmarking. 


\section{Annexes}

\section{Establishing the Purchasing Program}

The VRO financing team has developed clear, and increasingly detailed, strategy and organization development plans for the PHAP from mid 2017 up to the end of 2020. It also has a vision and outline plans covering the period from the beginning of 2021 to the end of Phase 2 at the end of 2025.

\section{Provider payment during Phase 1}

It is proposed that from January 2019 the PP will advise the Ministry of Finance how to allocate funds according to the following principles.

Capitation will commence with clusters at the beginning of 2019 , as quickly as data quality allows. Other providers will be paid by improved block budgets with target based incentive payments and penalties. Capitated clusters will receive a mix of:

- Full Capitation - Reflecting the gross cost of the EBP (including administration but excluding capital costs) for persons entitled to MoH coverage (adjusted to reflect those covered by OGS or CCHI); and

- Fractional Capitation - Reflecting the use of $\mathrm{MoH}$ facilities by OGS beneficiaries to obtain EBP services.

Capitated payments (prospective payments per person covered) will be the main payment mechanism. Capitated payments will be risk adjusted. The first basis of risk adjustment will be age and gender. During Phase 1 other bases for adjustment, including quality of services provided and deprivation, will be evaluated. Seasonal variations in expenditure may also need to be considered. It should be noted that it is not planned for the capitated payments to include provisions for capital assets and investments during Phase 1.

Key Performance Indicator (KPI) payments - Retrospective payments for performance against KPls.

Risk sharing arrangements - To be determined, to reflect external risks that impact on activity and outcome levels (e.g. communicable disease epidemics or major disasters). 


\section{Annexes}

Additional budget funding will be in the form of Structural Adjustment Support to reflect current $\mathrm{MoH}$ system inefficiencies. This support will be tapered to zero by the end of 2030 . A large proportion of this steadily reducing support will be passed on to $\mathrm{MoH}$ providers in the form of Structural Adjustment Grants (SAGs).

MoH providers may also receive budget funding for funded mandates, for services the $\mathrm{MoH}$ wishes to be provided but which are outside the EBP. This funding may be provided directly to $\mathrm{MoH}$ providers or channeled through the PHAP.

Other payments include mechanisms for paying specialist public hospitals not included in clusters. The PHAP will also make payments to domestic and international private providers for emergency overflows and selected elective services using funds allocated to it by the Ministry of Finance for those purposes.

\section{Provider payment during Phases 2 and 3}

From 2021 the PHAP will establish regional offices in proximity to provider regional corporates as needed. At some point during Phase 2 the PHAP will become an "armslength" corporatized public body with its own Board, with clearly demarked responsibilities, authorities and accountabilities. At the same time, the regulatory role of the PHAP will be separated from other responsibilities of the corporatized public body. It will be taken-up by a separate regulatory body.

Phase 3 envisages the extension of the National Health Insurance Scheme (NHI) to all citizens, residents and visitors to the Kingdom. The opportunity to purchase SHI will also be made available to most citizens, residents and visitors. These insurance policies will be provided via the introduction of an expanded, regulated, Saudi based, health insurance market. Providers of these policies, some existing private health insurance companies in the Kingdom, and new entrants including for profit and not for profit entities, are expected to include the PHAP.

The progress of the proposed financing reforms to Phases 2 and 3 is heavily contingent of the timely and successful development of the provider reforms. 


\section{Annexes}

\section{The development of health systems governance}

\section{Definition of health governance}

Based on a review of international literature, health governance has been defined as: "System of policies, regulations and structures to instill appropriate behaviors, monitor performance and optimize realization of health value to the population." [22]

\section{Governance work-stream approach}

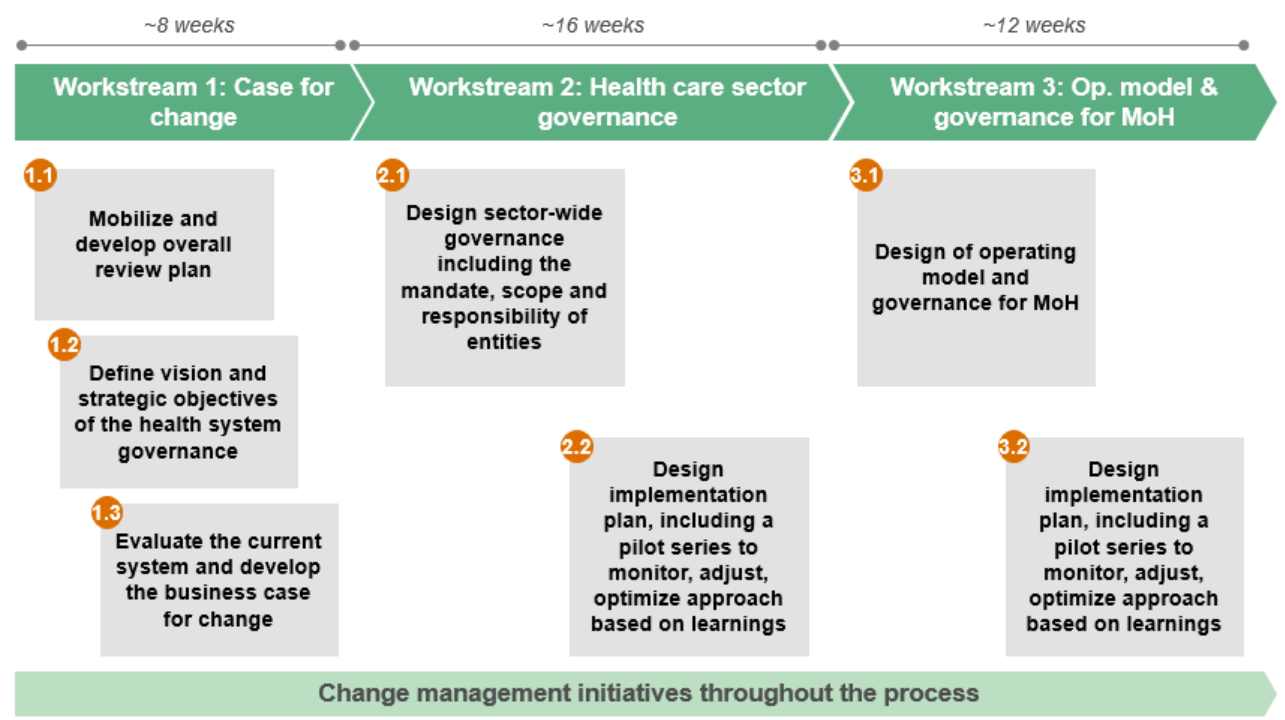

\section{Healthcare governance framework}

The assessment of the health system governance is based on a health system framework. This framework incorporates both horizontal and vertical pillars. The horizontal pillars represent the four core governance functions that apply across each of the vertical pillars. The vertical pillars themselves represent the key pillars that are found in a robust health system and are composed of multiple roles.

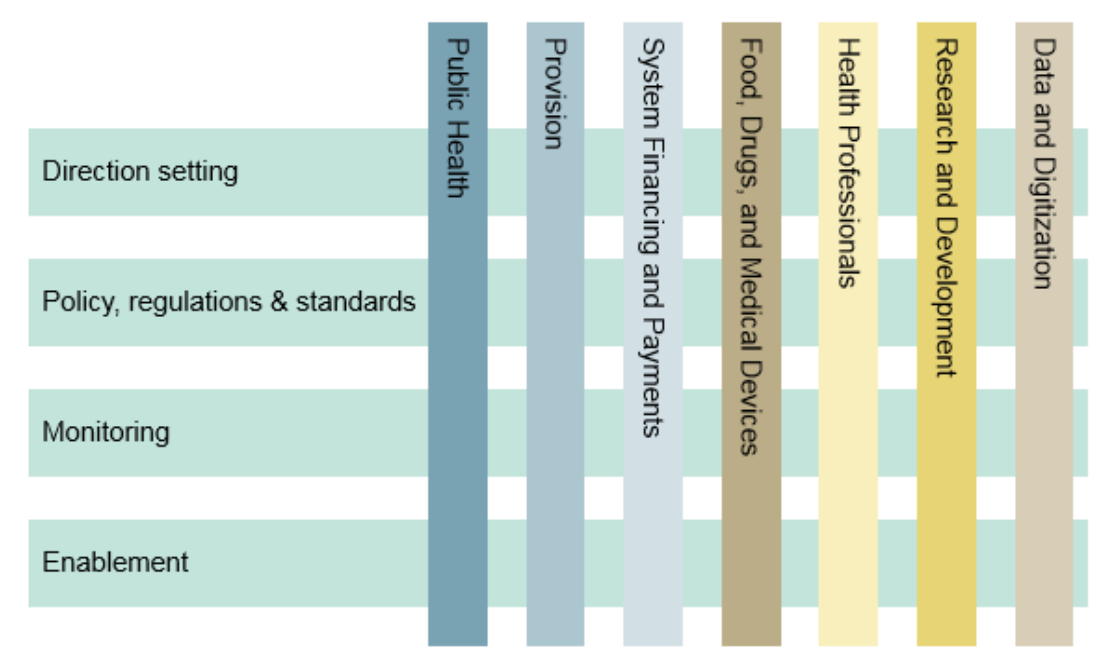




\section{Annexes}

The horizontal pillars in the framework are:

- Direction setting - Defines the key strategic objectives and priorities to steer the healthcare system.

- Policy, regulations and standards - Sets, maintains and develops regulatory framework and tools.

- Monitoring - Monitors compliance and system efficiency and effectiveness.

- Enablement - Provides the incentives, and support in building capabilities for continuous improvement.

\section{Current state assessment}

A three step process was undertaken to assess the implications on the future health governance in Saudi Arabia:

1. Saudi health system performance - This assessed the performance of the current health system.

2. Saudi health system governance structure assessment - This step identified the system-level governance pain points. Learning from that step is summarized in the slide below.

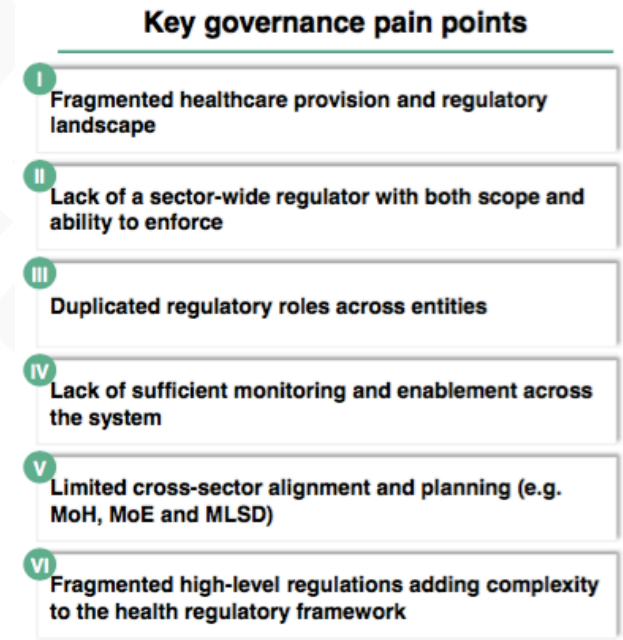

\begin{tabular}{l}
\multicolumn{1}{c}{ Implications on current state } \\
\hline $\begin{array}{l}\text { Inefficiencies in the healthcare access and cost } \\
\text { across the system }\end{array}$ \\
\hline $\begin{array}{l}\text { Challenging adoption of national policies and } \\
\text { regulations }\end{array}$ \\
\hline $\begin{array}{l}\text { Potential divergence in regulations and policies given } \\
\text { the lack of an ultimate decision maker }\end{array}$ \\
\hline $\begin{array}{l}\text { Disconnect between decision makers plans and } \\
\text { realities on the ground }\end{array}$ \\
\hline Sup-optimal alignment between health sector \\
demand and supply (e.g. health professionals, beds) \\
\hline Complex and lengthy process to adapt regulations to \\
the evolving sector needs
\end{tabular}

3. Saudi health system governance roles assessment - This step mapped current regulators against core functions and identified improvement opportunities. A summary is shown below. 


\section{Annexes}

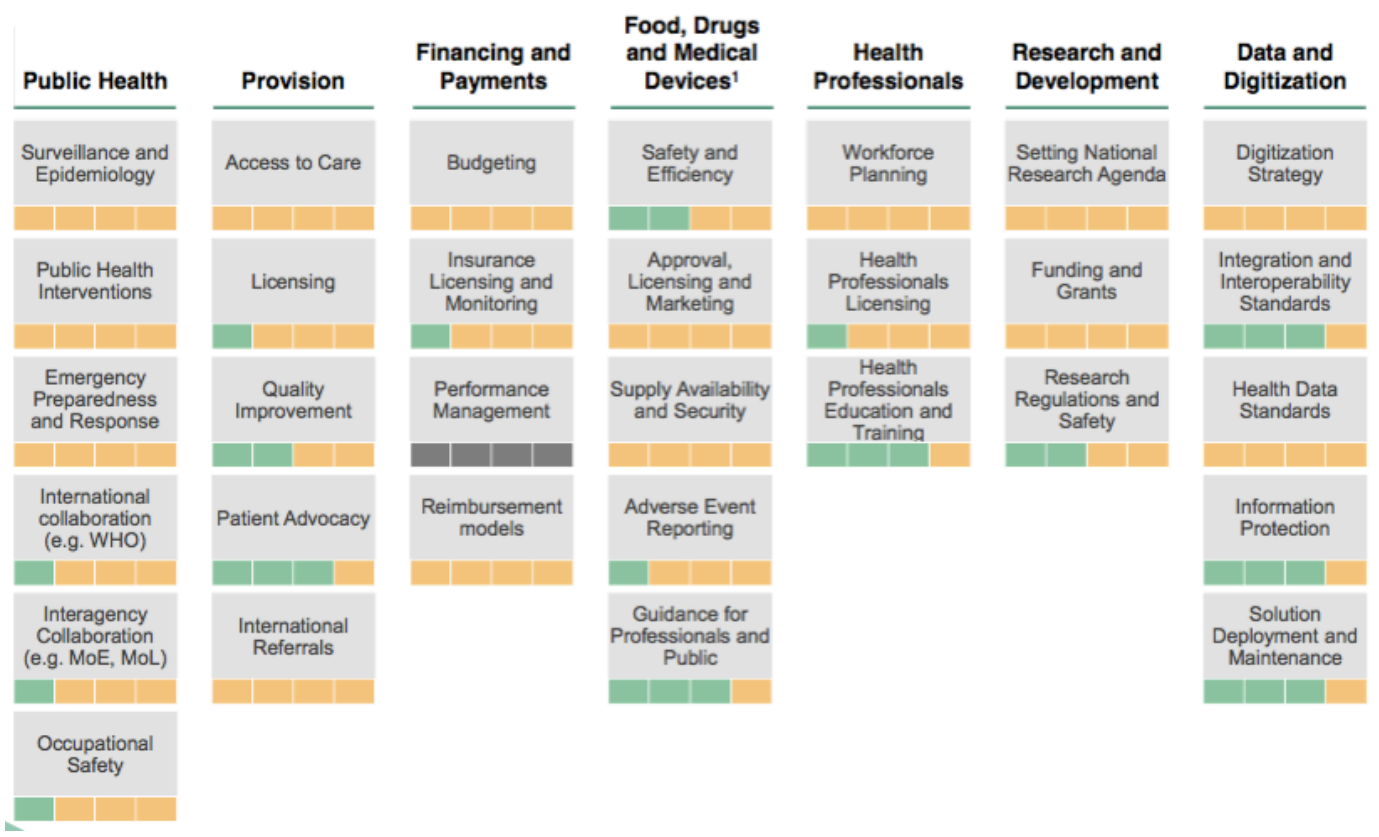

This assessment helped define the pillars of the future governance framework. For each vertical pillar the following requirements were identified:

\section{Public health}

- The need to have a national owner for public health.

- Balance the centralization and localization of public health programs to optimize delivery.

\section{Provision}

- Separate regulatory and provision roles in the $\mathrm{MoH}$.

- Consider having a national regulator for all healthcare provision and harmonize responsibilities.

- Institutionalize quality improvement mechanisms (i.e. data collection, analysis, and actions).

- Ensure objective and equal treatment of all health care providers.

\section{System financing and payment}

- The need to have a one sponsor or gate keeper for the national healthcare budget.

- Clarify who is regulating the PP.

- Institutionalize financial and clinical outcome analysis in preparation for a value based system.

- Expand scope and empower the insurance regulator. 


\section{Annexes}

Food, drugs and medical devices

- The need to strengthen the monitoring role of the Saudi Food and Drug Authority to ensure compliance of its regulations.

- Introduce a medication cost effectiveness role to enable providers to manage healthcare budgets.

Human capital

- Formalize workforce planning across health sector.

- Streamline the process of medical professional development from education, training, to joining the workforce.

- Separate setting training standards and licensing health workforce.

Research and development

- The need to centralize national research agenda setting and facilitation.

\section{Data and digitization}

- Empower the National Health Information Centre to lead healthcare digitization programs across the Kingdom.

- Formalize health data interoperability standards.

- Clarify business and clinical requirements coming out of the transformation on digital systems.

This assessment revealed commonalties and enabled the consolidation of the original pain points into four systemic points as outlined below:

\section{Healthcare Governance pain points}

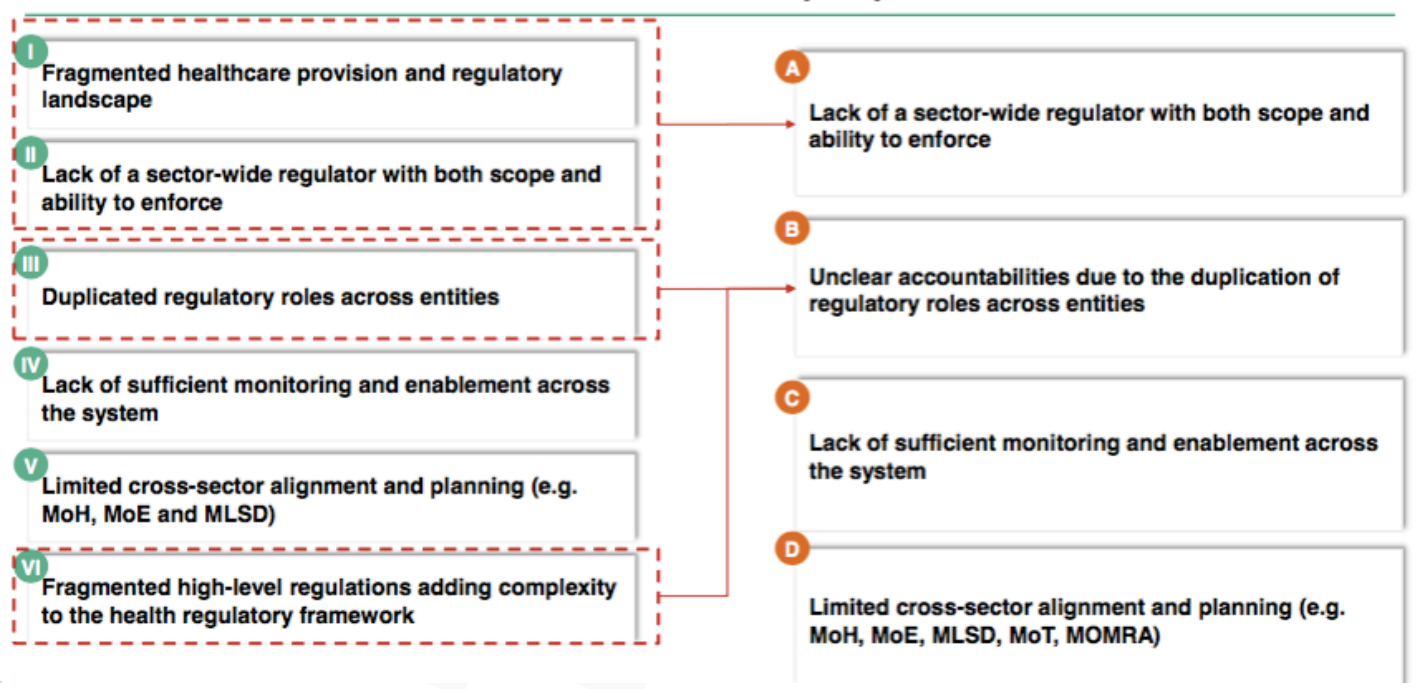

The new regulatory architecture (Work-steam 2.1) is presently being designed. This work should be completed by mid 2018. 


\section{Annexes}

\section{Private sector participation}

\section{What}

In January 2018, the workstream a detailed strategic context for private sector participation in the Kingdom. [23] It provided detailed information about nine principal areas:

1. Primary Care

2. Radiology

3. Laboratory services

4. The commissioning of hospital services and medical cities (completing, equipping and making operational partly built facilities; equipping and making operational built facilities; and making operational built and equipped facilities)

5. Extended care

6. Rehabilitation

7. Long Term Care

8. Home Care

9. Pharmacy

The strategic context includes a clear vision, a mission and value statements, five goals and 14 strategic objectives with associated five-year quantified targets. It also includes a theme alignment analysis, identifies key enablers, critical success factors and risks. It proposes a clear operating model with six business units, six pilot studies and a clear timeline for delivery over five years.

\section{The business model}

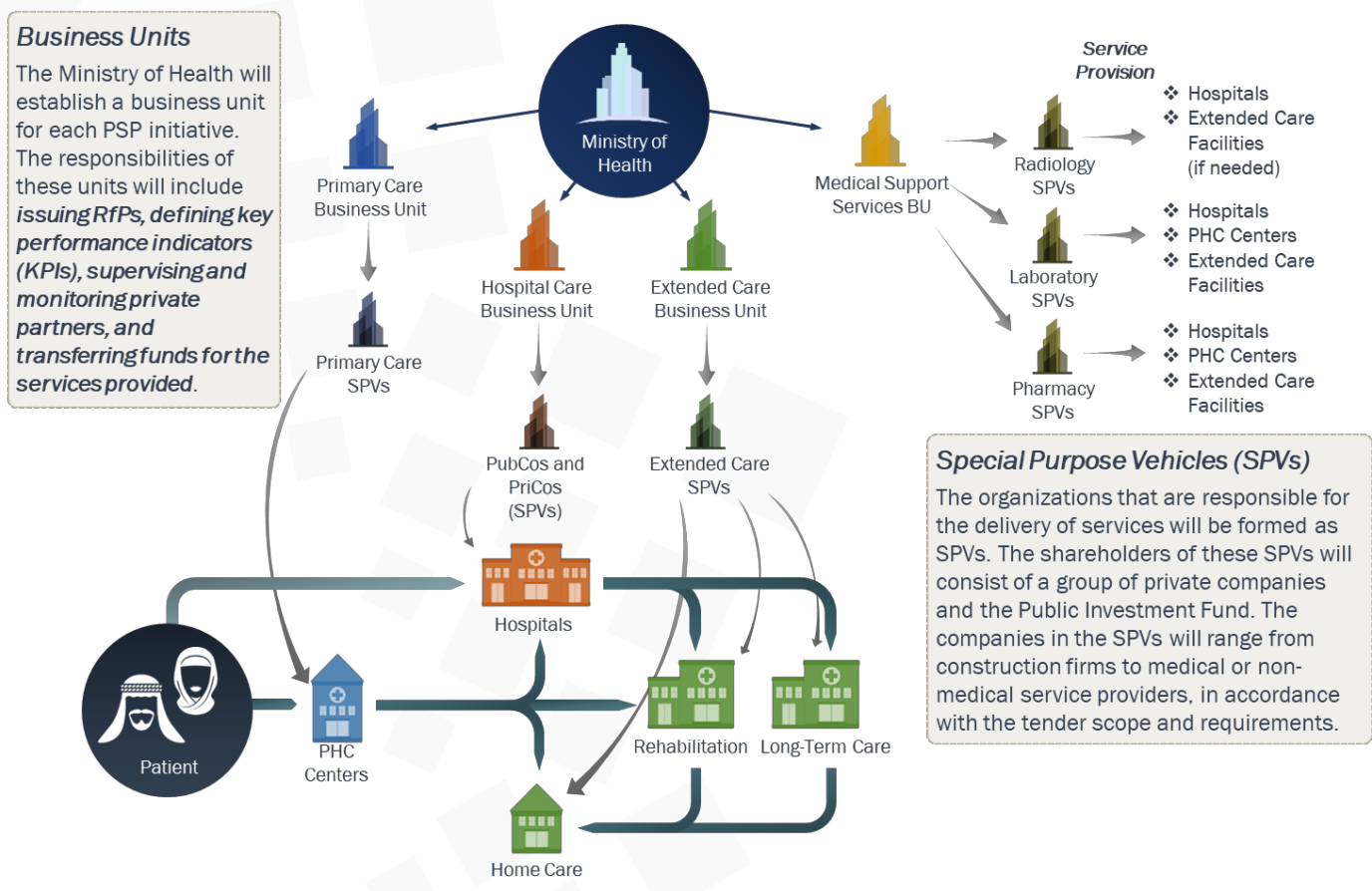




\section{Annexes}

\section{Third sector participation}

The $\mathrm{MoH}$ launched its Community Participation Program at the beginning of 2017. This was aligned to the recent trends that have been the relationship between the government and the community, and was supportive of the aspirations of Vision 2030 and NTP.

Community participation is based on the belief that health development can best be achieved through combining the efforts of both the government and all concerned parties. As the community's demand for health continues to grow and change this cooperation is essential.

The community has enormous resources and huge potential that can be used for its benefit and for solving health problems and challenges. However, the community cannot make an optimal contribution in the absence of a motivating environment and suitable opportunities to use its resources and potential.

Through the Community Participation Program, the $\mathrm{MoH}$ aims to become a partner that welcomes new and influential health partnerships with various components of the community, including individuals, civil societies and organizations, companies and government agencies.

The vision, mission, values, objectives, tracks and initiatives of the Community Participation Program are outlined below:

\section{Vision}

A community aware of its health challenges and actively participating in addressing them.

\section{Mission}

The Community Participation Program is a motivational and targeted platform that contributes to health development through effective and sustainable partnerships. It is built on proactivity, rapid response and an innovative approach between the $\mathrm{MoH}$ and all community components.

\section{Values}

1. Missional work.

2. Friendly environment.

3. Flexible performance.

4. Proactive workforces.

5. Effective initiatives. 


\section{Annexes}

\section{Objectives}

1. Directing the community resources to areas of priority.

2. Facilitating community participation in health development.

3. Maximizing the impact of community participation on health development.

4. Institutionalizing community participation in health development.

\section{Tracks}

1. Organizing and promoting charitable health activities.

2. Developing a volunteer system for health practitioners.

3. Building the capabilities of non-profit health entities and promoting their expansion.

4. Promoting health initiatives of community members.

\section{Initiatives}

1. Organizing and encouraging donations and endowments in the health sector.

2. Establishing a health charity fund.

3. The Community Partnerships Service Center. 


\section{Annexes}

\section{Workforce Development [24]}

The current national health workforce situation is characterized by:

- Low ratios of clinical staff (particularly nurses) to population levels, and health providers.

- Poor distribution of clinical staff and chronic shortage of staff in some regions.

- Low productivity of employed clinical staff.

- Limited numbers of prospective Saudi clinical staff in education;

- Low conversion rates from completion of clinical education in the KSA to MoH employment, particularly nursing staff.

- A limited number of medical and healthcare professional bodies (such as the Saudi Diabetes and Endocrine Association). [25]

- High reliance on expatriate clinical staff for both medical and nursing roles.

- Unquantified turnover of expatriate clinical staff (whether they are changing employers or leaving KSA.

- Unquantified medical and nursing capacity at specialty levels.

- Unquantified clinical and clinical support capacity in the following professions:

- Dentists

- Psychologists

- Physiotherapists

- Occupational therapists

- Laboratory technicians

- Major resource and expertise gaps in nonclinical healthcare professions including:

- Chairmen and Non-Executive Directors for newly corporatized entities

$\circ$ General management

- Finance

- Health economics

- Information and technology management

- Human resources

- Planning

- Estates

- Logistics

- Communications

- Legal 


\section{Annexes}

- Low perceived status of the nursing profession among the Saudi population;

- Poor and fragmented data and statistics about the KSA health workforce, for example the numbers trained or available for employment, employed; and

- Insufficient IT infrastructure to support workforce data management.

\section{Understanding workforce capacity and demand}

The VRO is currently working to analyze and allocate the attributes of the current workforce professionals in the Kingdom. This includes, but is not limited to, understanding location, specialties and sub-specialties per region and per facility, for all categories of staff. This work will provide an annual forecast of healthcare workforce demand and quantify the annual gap between supply and demand until 2030. The forecast will take into account drivers of supply and demand, include technological changes, changes to the Model of Care, and changes to the system resulting from corporatization.

\section{Building workforce capacity}

Within this work-stream the goal of the workforce strategy is to build national practice capacity in all specialties and sub-specialties. This will ensure fair distribution across the Kingdom based on needs. This includes an ambition to encourage qualified Saudi personnel (presently in the KSA or abroad) to re-enter the KSA health workforce. This may include (re-) education and (re-) training. There is also a program of work underway to improve the attractiveness of nursing and other healthcare professions. There may also be opportunities to recruit suitably qualified non-clinical staff from other sectors. This work is scheduled for completion by the end of 2018. Further detail on this project is shown below.
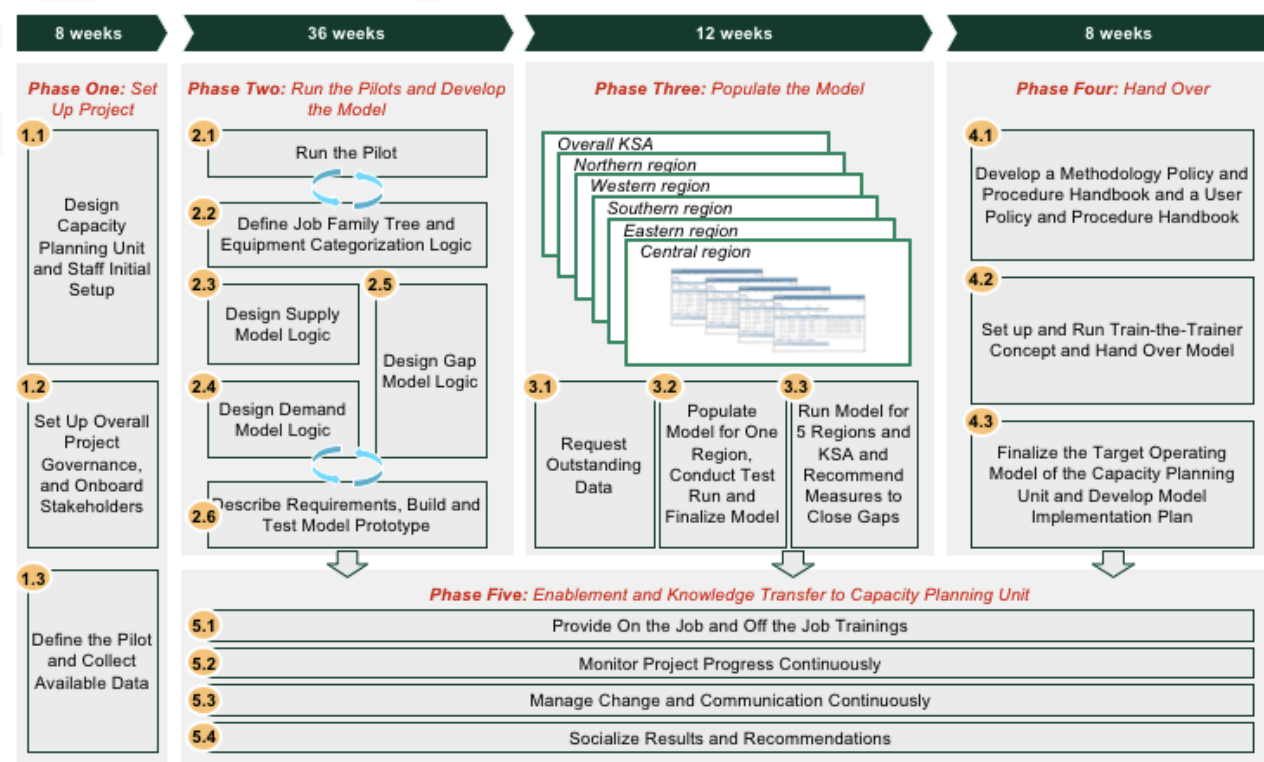

Phase Five: Enablement and Knowledge Transfer to Capacity Planning Unit
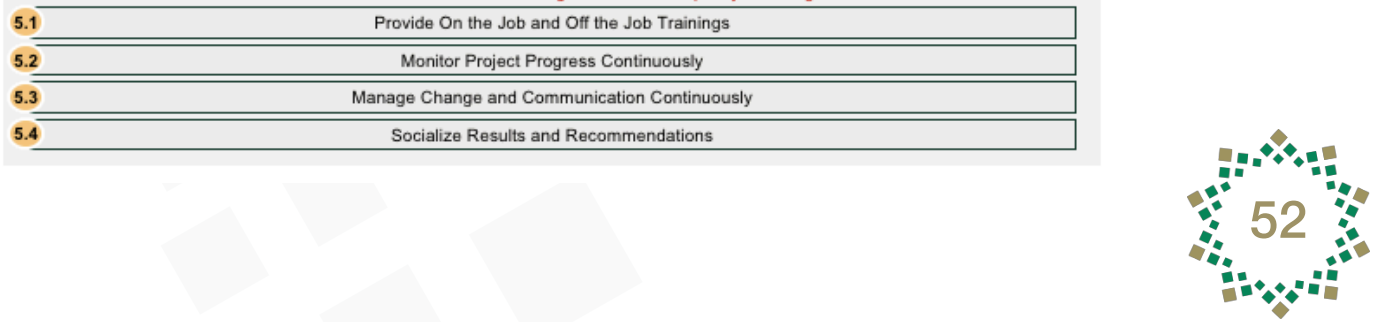


\section{Annexes}

\begin{tabular}{|c|c|c|c|}
\hline \multirow{4}{*}{ Scope } & Workforce & SCFHS & Capacity planning \\
\hline & Facilities & × & 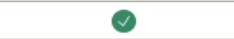 \\
\hline & Services & (2) & ? \\
\hline & Equipment & (8) & ? \\
\hline \multirow{4}{*}{$\begin{array}{l}\text { Precision of } \\
\text { parameters }\end{array}$} & Demographics & (2) & (2) \\
\hline & Disease burden & × & (2) \\
\hline & Model of care & $\times$ & ? \\
\hline & Education output & (8) & (2) \\
\hline \multirow{5}{*}{ Flexibility } & Data update & ○ & ? \\
\hline & Segmentation update & 8 & ( \\
\hline & Ratio evolution & 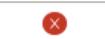 & 8 \\
\hline & Parameters update & × & (2) \\
\hline & Simulation update & 8 & (2) \\
\hline \multirow{3}{*}{ Granularity } & At facility level & $\otimes$ & (2) \\
\hline & At medical domain level & $\otimes$ & ? \\
\hline & At service area level & $\otimes$ & ? \\
\hline
\end{tabular}

\section{Building workforce capability}

As well as building workforce capacity there is the related goal to build capability through a national program covering all specialties and sub-specialties and targeted on the needs identified through the capacity planning work. This will include the accreditation of 50 hospitals as teaching hospitals offering training, and the establishment of five family medicine academies across the Kingdom. In 2017 the focus was on immediately developing training programs for the highest priority specialty and sub-specialty areas. There will then be a three-phase rollout of a national training program, with each phase lasting a year from 2018 to 2020. 


\section{Annexes}

\section{The development of eHealth [26]}

Digital health and healthcare, or eHealth, is the cost-effective and secure use of information and communication technologies in support of health and health-related goals. This includes healthcare services, health surveillance, health literature, and health education, knowledge and research. [27]

The effective adoption of eHealth will:

- Facilitate the introduction for radically different approaches to care;

- Ease the entrance into the health space for new, non-traditional players;

- Provide disease prediction tools;

- Enable customer empowered personal management of care; and

- Help alert population health systems of communicable disease outbreaks.

eHealth is a critical enabler of the system reform program described in this strategy. It is necessary to:

- Enable the adherence to and enforcement of health system quality and safety practices;

- Provide people with personalized digital tools to promote health management, health literacy and help navigate and interact with the health system;

- Integrate the continuum of health across all layers of the New Models of Care to support the flow of personal health information;

- Monitor operational efficiencies as well as the outcomes of services provided;

- Monitor and optimize the use of healthcare resources, such as workforce, assets and services;

- Provide access to high quality data to support medical research and policy making;

- Establish a Virtual Academy to build knowledge and skills necessary to deliver the New Models of Care interventions;

- To achieve the substantial efficiency gains across key corporate functions of provider organizations, including: finance, HR, IT, procurement, clinical services, clinical support services and quality control; 


\section{Annexes}

- Introduce activity based costing, patient accounting, revenue cycle and claims management;

- Implement clinical coding practices;

- Implement a data quality program; and

- Enable health system performance reporting.

Investment in eHealth in the Kingdom is expected to deliver multiple benefits. These include:

- Enhanced personal experience, convenience and responsibility - People will have new forms of interacting with the health system and consume health services differently. The physical healthcare system can be augmented with a virtual health system improving access to healthcare services whenever and wherever people are in need. eHealth will help people take more personal control over, and responsibility for, their lifestyle and health.

- $\quad$ Safer and more effective services - Healthcare is an information and knowledge intense industry. Critical healthcare decisions are made based on diagnostic and clinical information at hand. Real-time access to accurate information enables better assessment. This helps to avoid costly medical errors and adverse events caused by missing or wrong information.

- $\quad$ Productivity increases for healthcare practitioners - Skilled medical practitioners in the Kingdom are a scarce and expensive resource. eHealth can provide the medical workforce with the tools and capabilities to enhance their productivity by automating a majority of administrative tasks. It provides support by augmenting the decision-making process with digital information and knowledge capabilities that do not exist in the Kingdom today.

- Efficient and integrated system - More efficient use of healthcare resources is key for achieving a sustainable health system. eHealth will enable better integration of the various systems of healthcare from one care setting to another. A common definition of data will underpin this capability and ensure consistent information can be made available for treatment care. Making data more readily available will reduce duplication and inefficiency in its collection.

- Creation of a new knowledge industry - Implementing digital technologies is a challenge that requires a skilled labor force. Global experiences have shown that eHealth programs have established tens of thousands of job opportunities, as well as a significant number of health informatics startups by entrepreneurs. Investing in eHealth not only provides benefits to the health system, but also to the wider KSA economy. 


\section{Annexes}

The National Transformation Program 2020 outlines a key target that by $202070 \%$ of the Kingdom's population should have a Unified Health Record. This has been formalized as " $70 \%$ of the population will have at least one record in either of the four 2020 National eHealth Systems." Activities that contribute to the achievement of that goal are marked on the graphics below with a target.

\section{Implementing eHealth}

\section{Scope of the eHealth Strategy and the role of the Saudi Health Exchange}

The KSA eHealth strategy has important elements that are health sector wide, and will link the $\mathrm{MoH}$, other government services and private segments of the health system. The Saudi Health Exchange (SeHE) will be an important mechanism for integration of digital capabilities across all segments of the health system.

Solution classes, portfolios and programs

The implementation strategy presently comprises, three solution classes, four portfolios and 52 programs.

\section{Solution classes}

The three solution classes distinguish:

- National Solutions -Those that will be provided by one provider for all system segments (including national solutions specifically enabled by SeHE);

- Cluster Solutions - Those that may vary from MoH cluster to cluster (albeit to common data standards) and are intended to facilitate $\mathrm{MoH}$ cluster and then $\mathrm{ACO}$ enablement; and

- Enterprise solutions - Those that may be provided by multiple vendors (again to common core data standards) to all system segments.

The interrelationship of the solution classes and SeHE is illustrated below:

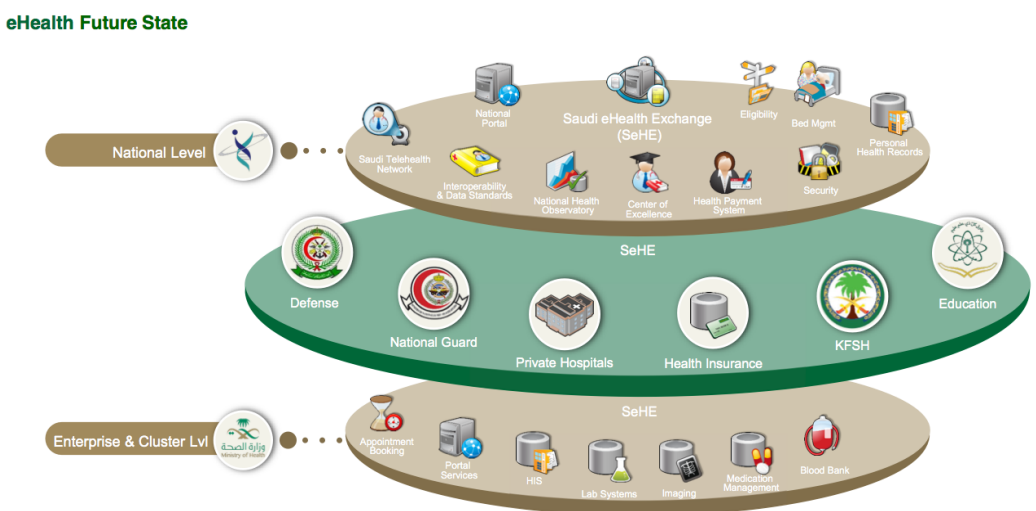




\section{Annexes}

\section{Portfolios}

The portfolios group individual programs by major function: clinical programs; infrastructure and operations; personal health services; and administrative services.

The apportionment of programs to the portfolios is shown in the graphics below. The tables also show, the class, timeline and key milestones of each program.
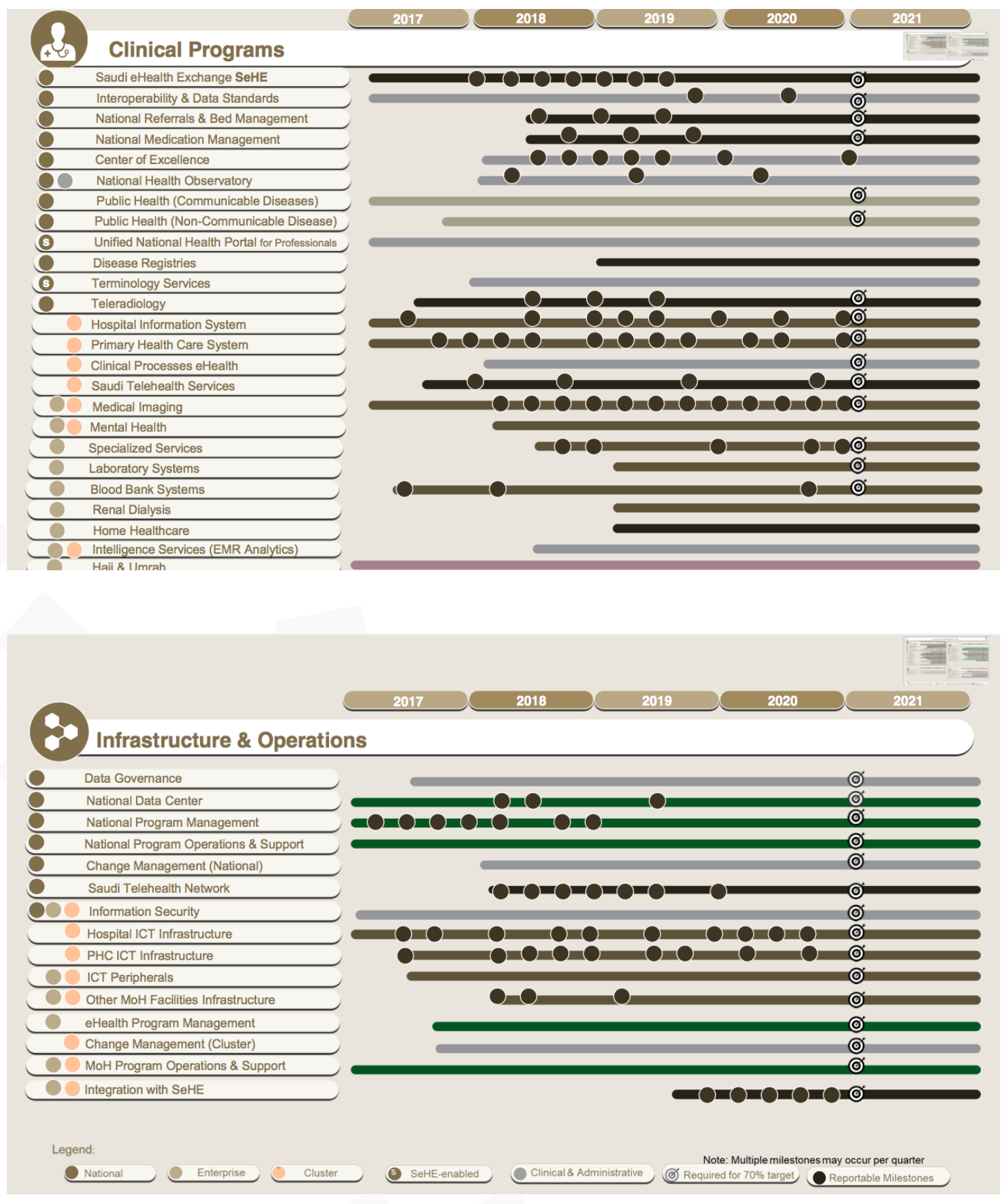


\section{Annexes}
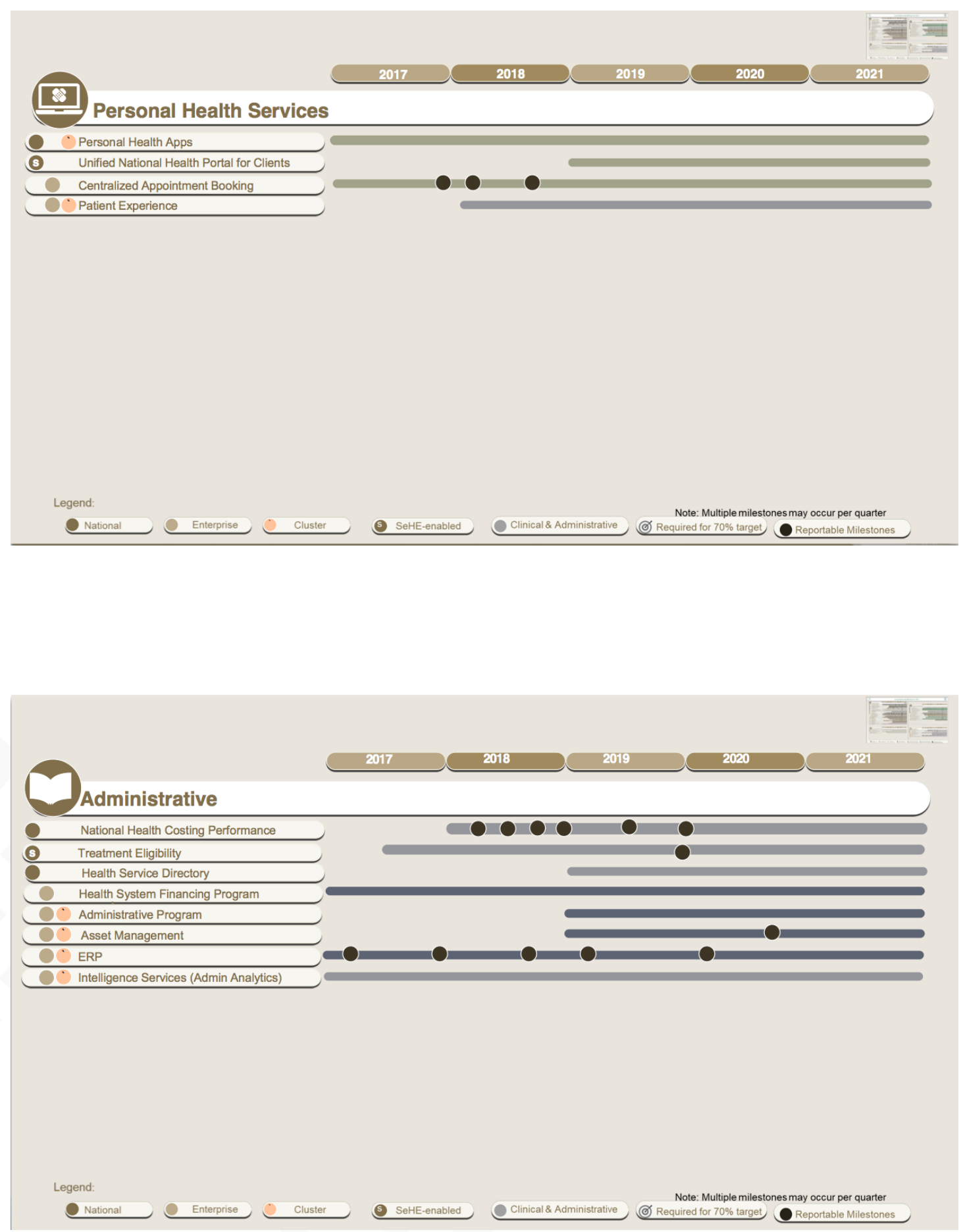


\section{Annexes}

\section{Annex B. A description and summary analysis of the Harvard and Oxford value frameworks}

\section{Introducing the frameworks}

Value in healthcare can be defined most simply as "outcome divided by cost."

The fundamental principles of value based healthcare in healthcare is to first align stakeholders around the shared objective of improving health outcomes delivered at a given cost. Then to give stakeholders the autonomy, tools and accountability to pursue the most rational ways of delivering value to all the people in need within the population. [28]

In some cases, people with specific needs generally reach the right service, for example people with limb fractures or cancers. For most health problems however, the need is not always so clear. People with conditions like depression, hip pain or asthma only reach the specialist service if they present to the primary care service and the primary care clinician recognizes the need for specialist help. In every country this is influenced by many factors which mean that:

- Those who reach the specialist service are not necessarily those who will benefit most; and

- Many of those who do not reach the specialist service would get greater benefit than those who have done so.

The population as a whole will derive more value if these mismatches were prevented.

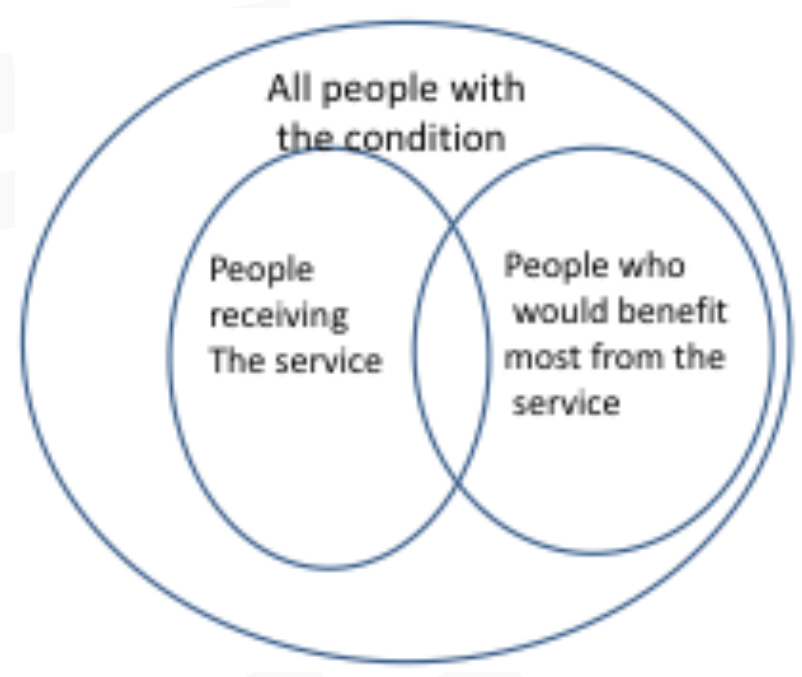




\section{Annexes}

The value-based approach to care rests on four foundational elements:

- Measuring systematically the allocation of resources to different sub-groups, for example people with cancer or people with mental health problems;

- Measuring health outcomes that matter to patients and the costs required to deliver those outcomes across the full cycle of care;

- Tracking those outcomes and costs for defined population segments on an ongoing basis, and

- Developing customized interventions to improve value for each population segment.

Five enablers are considered key to accelerating the adoption of value based healthcare:

- Health informatics, to facilitate the easy collection, analysis and sharing of outcomes and cost data;

- Benchmarking, research and tools, to leverage data on outcomes and the costs for clinical practice improvement and innovation;

- Value-based payments, to create incentives for all stakeholders to focus on value and a move away from activity based payment which encourage low value interventions;

- Innovations in organizing care delivery, to improve coordination across the health system with a single specification relevant to the whole Kingdom, with delivery being delegated to local networks; and

- A new culture that promotes collaboration and stewardship.

\section{The Harvard framework - Value based healthcare delivery [29]}

The Harvard framework focuses principally on optimizing value at the level of individual patients who have presented for treatment. It contains the systematic reduction of unwarranted variation in treatment selection, outcomes and costs.

The Harvard framework also concerns itself with optimizing clinical micro-systems within various institutional frameworks; and the optimization of treatment for defined populations or groups with identical or related diagnoses. 


\section{Annexes}

The Harvard framework reflects the historic market driven context of healthcare funding and delivery in the USA. This is where there is a highly inefficient distribution of services (mediated in large part through voluntary private health insurances) and has reflected the ability to pay more than ability to benefit. The Harvard framework does not address evidence based optimization of defined or limited resources in the system, and the associated trade-offs between different services and dissimilar patients. Nor does the framework address the evidence based optimization in distributing preventive, curative, care and palliative services for a defined population.

\section{The Oxford framework - Higher value healthcare [30]}

In contrast the Oxford framework reflects the historic UK and European context in which governments have greater control over the distribution healthcare either through public expenditure or government mandate.

The additional insight of the higher value healthcare framework developed at Oxford University is that, in systems that are fully and actively committed to the health and healthcare of their entire population, such as the Kingdom, an emphasis on personal value needs to be complemented by:

- A focus on allocative efficiency at the intermediate level; and

- The active identification of people who are not receiving care, but who may derive more value than those have been referred for treatment. The Kingdom, through its policy of total population coverage, is committed to reducing inequity as well as increasing efficiency.

To that end the framework defines three dimensions of value:

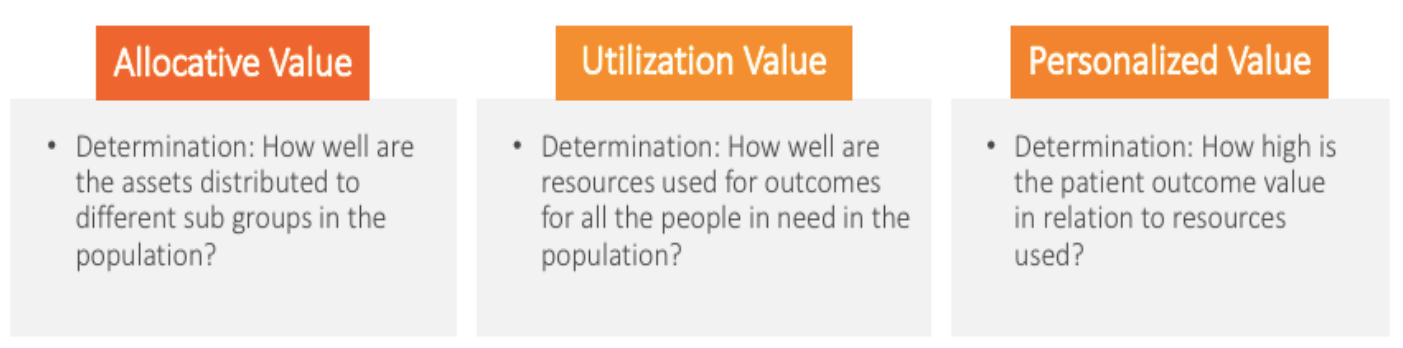

The higher value healthcare framework is particularly valuable in the Kingdom as it helps to distinguish not only different types of value, but also three distinct system levels at which value can be secured:

- At a national level

- At a sub-population level defined not only geographically but also by need

- At an individual level 


\section{Annexes}

The ambition to improve allocative and utilization value at both national and sub-population levels also links directly to the related concept of population health management (PHM). This has been defined as "the technical field of endeavor which utilizes a, variety of individual, organizational and cultural interventions to help improve the morbidity patterns and the health care use behavior of defined populations". PHM is distinguished from disease management by including more chronic conditions and diseases, by use of "a single point of contact and coordination", and by "predictive modelling across multiple clinical conditions" [31]. It introduces a third dimension to healthcare and is defined as population healthcare defined by being focused on people with a common symptom such as back pain, or people with the same condition such as breast cancer, or people with a common characteristic such as people in the last year of life; and not on institutions or specialties or technologies. This is the third dimension of health care.

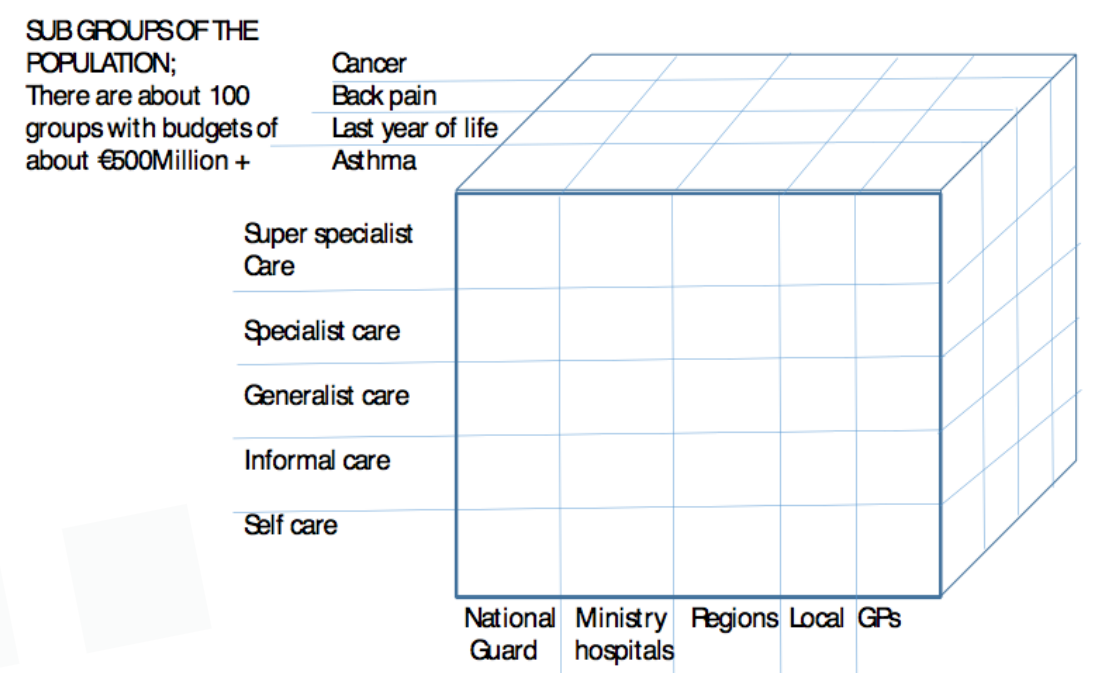

BUREAUCRAGES, 


\section{Annexes}

\section{Annex C. Bibliography of key documents}

Atun, R., Kruk M. et al, Saudi Arabia Health System Strategy Project, May 2017, Harvard University, School of Public Health

Dzau, Victor J., Mark B. McClellan, et al (2017) Vital Directions for Health and Health Care: Priorities from a National Academy of Medicine Initiative. . JAMA. Published online Mar 21 2017. doi: 10.1001/jama.2017.1964

KSA, MoH, eHealth Strategy, Version: Final for approval, 13 July 2017

KSA, MoH, eHealth Roadmap (draft updated), .ppt, December 2017

KSA MoH, VRO, Business Case for the Health System Reform Component of the Kingdom of Saudi Arabia's Vision 2030 Program, Version 2.0, 31 May 2017

KSA, MoH, VRO, Corporatization Update Meeting, 18 October 2017

KSA, MoH, VRO, Model of Care, .ppt presentation, October 2017

KSA, MoH, VRO, Private Sector Participation (PSP) in Healthcare, Commercial Prospectus, undated (2017)

Ministry of Health, Healthcare system financing strategy for the Kingdom of Saudi Arabia, (Draft at October 2017)

Ministry of Health, Healthcare workforce strategy (2017-2030), .ppt, May 2017

Saltmann R., J Figuaras, C Sakellarides (1998), Critical Challenges for Healthcare Reform, Open University Press, UK

Walshe K. and J. Smith (2006), Healthcare Management, Open University Press UK. 


\section{Annexes}

\section{Annex D. Endnotes}

1 KSA Vision 2030, Strategic Objectives and Vision Realization Programs, pdf, undated

2 KSA MoH VRO, Ministry of Health Transformation Journey, Supervisory Committee, 12 December 2017

3 https://en.wikipedia.org/wiki/Hajj\#Number_of_pilgrims_per_year

4 KSA MoH VRO, Business Case for the Health System Reform Component of the Kingdom of

Saudi Arabia's Vision 2030 Program, Version 2.0, 31 May 2017

5 http://www.wpro.who.int/health_services/health_systems_framework/en/

$6 \mathrm{http}: / /$ siteresources.worldbank.org/HEALTHNUTRITIONANDPOPULATION/Resources/

281627-1095698140167/HealthSystemsAnalysisForBetterHealthSysStrengthening.pdf

7 http://www.ihi.org/Engage/Initiatives/TripleAim/Pages/default.aspx

8 https://nam.edu/initiatives/vital-directions-for-health-and-health-care/

9 https://www.england.nhs.uk/five-year-forward-view/

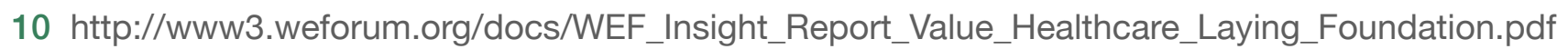

$11 \mathrm{https}: / /$ www.phc.ox.ac.uk/research/value-based-healthcare

12 Saltmann R., et al (1998)

$13 \mathrm{KSA}, \mathrm{MoH}, \mathrm{VRO}$, Model of Care, .ppt presentation, October 2017

$14 \mathrm{KSA}, \mathrm{MoH}, \mathrm{VRO}$, Corporatization Update Meeting, 18 October 2017

15 https://openknowledge.worldbank.org/handle/10986/15145

16 https://www.leadershipacademy.nhs.uk/wp-content/uploads/2013/06/NHSLeadership-

HealthyNHSBoard-2013.pdf

17 Ministry of Health, Healthcare system financing strategy for the Kingdom of Saudi Arabia, (Draft at October 2017)

$18 \mathrm{KSA}, \mathrm{MoH}, \mathrm{VRO}$, [Financing] Strategy Alignment, May 2017

19 http://www3.weforum.org/docs/WEF_Insight_Report_Value_Healthcare_Laying_Foundation.pdf 20 Shacklady Smith A., Chapter 22: Appreciating the challenge of change in Walshe and Smith (2006)

$21 \mathrm{KSA}$ MoH VRO, Business Case for the Health System Reform Component of the Kingdom of Saudi Arabia's Vision 2030 Program, Version 2.0, 31 May 2017

$22 \mathrm{KSA}, \mathrm{MoH}, \mathrm{VRO}$, correspondence with Governance work theme, 26 March 2018

$23 \mathrm{KSA}, \mathrm{MoH}, \mathrm{VRO}$, Private Sector Participation in Healthcare, Strategic Framework, .ppt, January 2017

24 Ministry of Health, Healthcare workforce strategy (2017-2030), .ppt, May 2017

25 http://sdea.org.sa/

$26 \mathrm{KSA}, \mathrm{MoH}, \mathrm{VRO}$, eHealth Strategy, v38, .ppt, 7 May 2017 and KSA, MoH, eHealth Strategy,

Final for approval 13 July 2017

27 http://www.who.int/gb/ebwha/pdf_files/WHA58/WHA58_28-en.pdf

28 http://www3.weforum.org/docs/WEF_Insight_Report_Value_Healthcare_Laying_Foundation.pdf 29 https://www.isc.hbs.edu/health-care/vbhcd/Pages/default.aspx

30 https://www.phc.ox.ac.uk/research/value-based-healthcare

31 https://en.wikipedia.org/wiki/Population_health\#Population_health_management_(PHM) 


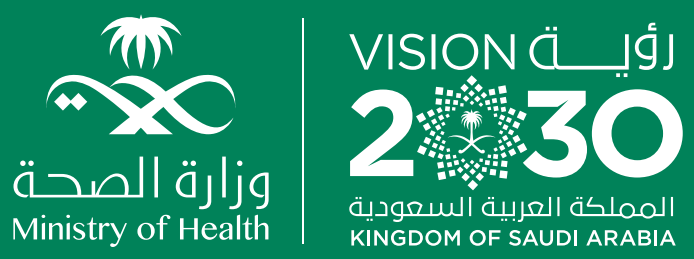

